\title{
Synaptophysin Regulates Fusion Pores and Exocytosis Mode in Chromaffin Cells
}

\author{
Che-Wei Chang, ${ }^{1,3 *}$ Yu-Tien Hsiao, ${ }^{2 *}$ and ${ }^{\circledR}$ Meyer B. Jackson ${ }^{2,3}$ \\ ${ }^{1}$ J. David Gladstone Institutes, University of California, San Francisco, California 94158, ${ }^{2}$ Department of Neuroscience, University of Wisconsin- \\ Madison, Madison, Wisconsin 53705, and ${ }^{3}$ Physiology Graduate Training Program, University of Wisconsin-Madison, Madison, Wisconsin 53706
}

Synaptophysin (syp) is a major integral membrane protein of secretory vesicles. Previous work has demonstrated functions for syp in synaptic vesicle cycling, endocytosis, and synaptic plasticity, but the role of syp in the process of membrane fusion during $\mathrm{Ca}^{2+}$-triggered exocytosis remains poorly understood. Furthermore, although syp resides on both large dense-core and small synaptic vesicles, its role in dense-core vesicle function has received less attention compared with synaptic vesicle function. To explore the role of syp in membrane fusion and dense-core vesicle function, we used amperometry to measure catecholamine release from single vesicles in male and female mouse chromaffin cells with altered levels of syp and the related tetraspanner protein synaptogyrin (syg). Knocking out syp slightly reduced the frequency of vesicle fusion events below wildtype (WT) levels, but knocking out both syp and syg reduced the frequency 2 -fold. Knocking out both proteins stabilized initial fusion pores, promoted fusion pore closure (kiss-and-run), and reduced late-stage fusion pore expansion. Introduction of a syp construct lacking its C-terminal dynamin-binding domain in syp knock-outs (KOs) increased the duration and fraction of kiss-and-run events, increased total catecholamine release per event, and reduced late-stage fusion pore expansion. These results demonstrated that syp and syg regulate dense-core vesicle function at multiple stages to initiate fusion, control the choice of mode between full-fusion and kiss-and-run, and influence the dynamics of both initial and late-stage fusion pores. The transmembrane domain (TMD) influences small initial fusion pores, and the C-terminal domain influences large latestage fusion pores, possibly through an interaction with dynamin.

Key words: chromaffin cells; dense-core vesicle; exocytosis; fusion pores; secretion; synaptophysin

Significance Statement

The secretory vesicle protein synaptophysin (syp) is known to function in synaptic vesicle cycling, but its roles in dense-core vesicle functions, and in controlling membrane fusion during $\mathrm{Ca}^{2+}$-triggered exocytosis remain unclear. The present study used amperometry recording of catecholamine release from endocrine cells to assess the impact of syp and related proteins on membrane fusion. A detailed analysis of amperometric spikes arising from the exocytosis of single vesicles showed that these proteins influence fusion pores at multiple stages and control the choice between kiss-and-run and full-fusion. Experiments with a syp construct lacking its $C$ terminus indicated that the transmembrane domain (TMD) influences the initial fusion pore, while the $\mathrm{C}$-terminal domain influences later stages after fusion pore expansion.

\section{Introduction}

$\mathrm{Ca}^{2+}$-triggered exocytosis from neurons and endocrine cells requires three soluble $\mathrm{N}$-ethylmaleimide-sensitive factor attachment

\footnotetext{
Received Nov. 9, 2020; revised Feb. 1, 2021; accepted Feb. 26, 2021.

Author contributions: M.B.J., C.-W.C., and Y.-T.H. designed research; C.-W.C. and Y.-T.H. performed research; M.B.J., C.-W.C., and Y.-T.H. analyzed data; M.B.J. and C.-W.C. wrote the paper.

${ }^{*}$ C.-W.C. and Y.-T.H. are co-first authors.

This work was supported by the National Institutes of Health Grant NS44057. We thank Chung-Wei Chiang and Ed Chapman for helpful discussions and comments on the manuscript. Ed Chapman provided the WT syp and syp-dC constructs. We also thank Randall Massey for assistance with the electron microscopy.

The authors declare no competing financial interests.

Correspondence should be addressed to Meyer B. Jackson at meyer.jackson@wisc.edu.

https://doi.org/10.1523/JNEUROSCI.2833-20.2021

Copyright $\odot 2021$ the authors
}

receptor (SNARE) proteins. Two of these SNARE proteins, syntaxin 1 and SNAP-25, reside in the plasma membrane and the third, synaptobrevin 2, resides in the vesicle membrane. The SNARE motifs of these proteins associate into a helical bundle to provide the driving force for fusion (Hanson et al., 1997; Sutton et al., 1998; Fasshauer, 2003), and the transmembrane domains (TMDs) of syntaxin and synaptobrevin contribute to the formation of the initial fusion pore (Chang et al., 2017; Chiang et al., 2018). It is well established that the SNARE proteins participate directly in exocytotic membrane fusion, and their interactions change as the vesicle and plasma membranes join together (Chen et al., 1999; Hua and Charlton, 1999; Xu et al., 1999; Wei et al., 2000; Sørensen et al., 2002, 2006; Han and Jackson, 2006; Kesavan et al., 2007). These studies support the concept that the SNAREs constitute the minimal molecular machinery for biological membrane fusion (Weber 
et al., 1998; Jackson and Chapman, 2006; Südhof and Rothman, 2009).

In contrast to the SNAREs, it remains unclear whether synaptophysin (syp), an integral membrane protein of secretory vesicles with four TMDs, plays a role in membrane fusion. Syp is the most abundant protein of synaptic vesicles by mass, accounting for $\sim 10 \%$ of a vesicle's total protein (Takamori et al., 2006). Studies to date point to a role for syp in vesicle cycling. Syp regulates clathrin-dependent endocytosis of synaptic vesicles (Daly et al., 2000) by interacting with dynamin through its C-terminal domain (Daly and Ziff, 2002). Syp also mediates the postfusion retrieval of synaptic vesicles in hippocampal neurons, with its $\mathrm{C}$ terminus functioning in a rapid phase of endocytosis during electrical activity (Kwon and Chapman, 2011).

Although initially thought to be associated with small synaptic vesicles rather than large dense-core vesicles (LDCVs; Walch-Solimena et al., 1993), syp is now recognized to reside on LDCVs in endocrine cells (Obendorf et al., 1988; Fournier et al., 1989; Lah and Burry, 1993; Winkler, 1997; Fukuda et al., 2002; González-Jamett et al., 2010) and has been implicated in their function. Injection of anti-syp antibody increases the duration and quantal size of $\mathrm{Ca}^{2+}$-triggered exocytotic events in chromaffin cells, and this action is mediated by the interaction of the syp C terminus with dynamin (González-Jamett et al., 2010). Furthermore, syp associates strongly with synaptobrevin (Calakos and Scheller, 1994; Edelmann et al., 1995; Becher et al., 1999), and electron microscopy revealed a pore-like sypsynaptobrevin complex with 6 syps and 12 synaptobrevins forming a hexameric ring (Adams et al., 2015). The inward-facing residues of the synaptobrevin TMDs in this structure have been implicated as fusion pore liners in both endocrine (Chang et al., 2015) and synaptic (Chiang et al., 2018) fusion pores. Syp is related to other vesicle membrane proteins with four TMDs (tetraspanners), including synaptogyrin (syg), synaptoporin, and secretory carrier-associated membrane proteins (SCAMPs; Hübner et al., 2002). Syg has been shown to function in exocytosis in PC12 cells (Sugita et al., 1999), and its ablation in Drosophila reduces spontaneous release (Stevens et al., 2012).

Prior work has demonstrated a number of roles for syp and related tetraspanners, but has left important questions unanswered about how these proteins function in the actual fusion of membranes during exocytosis. To address these questions, we used amperometry to record catecholamine release from chromaffin cells prepared from syp knock-out (KO) and syp/syg double $\mathrm{KO}(\mathrm{DKO})$ mice, as well as chromaffin cells expressing syp constructs. Our results reveal functions for syp and syg in multiple stages of membrane fusion. These proteins influence the dynamics of initial and late-stage fusion pores, and control the choice between full-fusion and kiss-and-run. Results with a syp deletion truncation construct indicate that the TMDs of syp stabilize initial fusion pores, while the C-terminal domain modulates a larger late-stage fusion pore.

\section{Materials and Methods}

\section{Syp KO and syp/syg DKO chromaffin cells}

Homozygous syp KO mice were obtained by crossing syp heterozygous KO animals (Eshkind and Leube, 1995), and littermates harboring the syp gene were used as wild-type (WT) control. DKO syp/syg animals were obtained by crossing homozygous syp and heterozygous syg $\mathrm{KO}$ animals (Janz et al., 1999). Chromaffin cells were also prepared from WT mice for pharmacological experiments.

Cultured chromaffin cells were prepared from newborn [postnatal day (P)0)]pups. Fresh adrenal glands were dissected in ice cold HBSS and digested in DMEM containing 20 units of papain at $37^{\circ} \mathrm{C}$ for $20 \mathrm{~min}$ (Sørensen et al., 2003). Papain solution was then replaced with DMEM containing penicillin/streptomycin and insulin-transferrin-seleniumethanolamine (ITS-X; Invitrogen\#51500056), and adrenal glands were dissociated into single cells by trituration. Individual pups were genotyped and their cells cultured on separate poly-D-lysine coated cover slips.

\section{Molecular biology and virus transfection}

DNA encoding rat WT syp and syp-dC were obtained from Edwin Chapman (Kwon and Chapman, 2011). Syp-dC comprises amino acids 1-243, which includes the four TMDs but lacks the large C-terminal domain. These sequences were subcloned into a bicistronic lentiviral vector pLox-CMV-IRES2-EGFP (modified from Gascón et al., 2008). WT and mutant constructs were confirmed by sequencing. To generate lentiviral vectors, HEK $293 \mathrm{~T}$ cells were co-transfected by the calcium phosphate method with three plasmids: pLox-CMV-Syp-IRES2-EGFP or mutants, pCAG-VSVg (expressing the VSV-G envelope protein) and pCMV- $\Delta 8.9$ (expressing the gag/pol proteins); $48-60 \mathrm{~h}$ later the supernatant was collected, run through $0.45-\mu \mathrm{m}$ filters, and centrifuged at $70,000 \times g$ for $2 \mathrm{~h}$. The concentrated viral particles were resuspended with $100-\mu \mathrm{l}$ PBS ( $\mathrm{pH}$ 7.4) and stored at $-80^{\circ} \mathrm{C}$. Chromaffin cells on one cover slip were infected with $10 \mu \mathrm{l}$ of viral particles on the day of dissection.

\section{Amperometry}

Chromaffin cells $1-3 \mathrm{~d}$ in vitro were bathed at room temperature (RT; $\sim 22^{\circ} \mathrm{C}$ ) in a solution consisting of $150 \mathrm{~mm} \mathrm{NaCl}, 4.2 \mathrm{~mm} \mathrm{KCl}, 1 \mathrm{~mm}$ $\mathrm{NaH}_{2} \mathrm{PO}_{4}, 0.7 \mathrm{~mm} \mathrm{MgCl}_{2}, 2 \mathrm{~mm} \mathrm{CaCl}$, and 10 mm HEPES (pH 7.4). Catecholamine release was measured with amperometry using a VA-10 amplifier (ALA Scientific Instruments) and $5-\mu \mathrm{m}$ carbon fiber electrode (ALA Scientific Instruments) polarized to $650 \mathrm{mV}$ (Wang et al., 2006). GFP fluorescence identified transfected cells. To elicit exocytosis a depolarizing solution (identical to the bathing solution but with $105 \mathrm{~mm} \mathrm{KCl}$ and $5 \mathrm{~mm} \mathrm{NaCl}$ ) was pressure ejected from a $\sim 2-\mu \mathrm{m}$ tipped micropipette positioned with a micromanipulator $10-15 \mu \mathrm{m}$ from the cell. Amperometric current was recorded in 23-s episodes, starting with a 3-s baseline, followed by a 6-s application of depolarizing solution, and continuing another $14 \mathrm{~s}$. This was repeated up to six times for each cell.

Amperometry recordings were analyzed with an in-house computer program that locates exocytotic events and computes various properties (Figs. 5A, 7A). Analysis generally focused on events with amplitude $\geq 2 \mathrm{pA}$ and duration $\geq 3 \mathrm{~ms}$. Kiss-and-run events were defined on the basis of amplitudes between 2 and 4 or 2 and $6 \mathrm{pA}$, and spikes were defined on the basis of amplitudes $>4$ or $>6 \mathrm{pA}$ (see Results; Fig. 5). To construct cumulative spike count plots (Fig. $2 C$ ), events from the first $\mathrm{KCl}$ stimulation with amplitude $>4 \mathrm{pA}$ were pooled, binned at one second intervals, and divided by the number of cells for that condition. The curve rose linearly between $10 \%$ and $70 \%$ of the plateau, and this rising portion was fitted by linear regression. Prespike foot (PSF) duration was determined according to a protocol described by Chow and von Rüden (1995), and distributions fitted to a single exponential. Analysis of PSF (Fig. 6) used PSF with durations $\geq 0.75 \mathrm{~ms}$ associated with spikes $\geq 20$ pA. Analysis of spike characteristics (Figs. 7, 8) used spikes $\geq 20$ pA.

\section{Whole-cell patch clamp of $\mathrm{Ca}^{2+}$ current}

Chromaffin cells were bathed at RT in a solution consisting of $105 \mathrm{~mm}$ $\mathrm{NaCl}, 20 \mathrm{~mm} \mathrm{CaCl}_{2}, 1.5 \mathrm{~mm} \mathrm{MgSO}_{4}, 5 \mathrm{~mm}$ HEPES, $15 \mathrm{~mm}$ glucose, and 3 $\mu \mathrm{M}$ tetrodotoxin, $\mathrm{pH}$ 7.4. Patch pipettes had resistances of 3-7 $\mathrm{M} \Omega$ when filled with a solution consisting of $90 \mathrm{~mm} \mathrm{~N}$-methylglucamine-Cl, $20 \mathrm{~mm}$ TEA-Cl, 0.2 mм EGTA, 2 mm $\mathrm{MgCl}_{2}, 10 \mathrm{~mm}$ HEPES, $20 \mathrm{~mm} \mathrm{Na} \mathrm{N}_{2}$-creatine phosphate, $5 \mathrm{~mm} \mathrm{Mg-ATP}$, and $0.1 \mathrm{~mm} \mathrm{Na}_{3}-\mathrm{GTP}$, pH 7.4. Current responses were recorded to $100-\mathrm{ms}, 10-\mathrm{mV}$ pulses from a holding potential of $-80 \mathrm{mV}$. Signals low-pass-filtered at $1 \mathrm{kHz}$ were recorded with an Axon 200B patch-clamp amplifier (Molecular Devices), and digitized with a Digidata $1550 \mathrm{~B}$ interface (Molecular Devices) at $4 \mathrm{kHz}$ using pClamp10 software (Molecular Devices). Peak $\mathrm{Ca}^{2+}$ currents during the $10-\mathrm{mV}$ depolarizing pulse were averaged, and evaluated statistically by one-way ANOVA. Bar graph displays mean \pm SEM. 
Immunocytochemistry and confocal imaging

Chromaffin cells on cover slips were fixed with $4 \%$ paraformaldehyde at RT for $15 \mathrm{~min}$, permeabilized with $0.1 \%$ Triton X-100 for $10 \mathrm{~min}$, and blocked in $10 \%$ goat serum and $3 \%$ bovine serum albumin at RT for $1 \mathrm{~h}$. Cells were then incubated at $4^{\circ} \mathrm{C}$ overnight with mouse anti-syp antibody (Synaptic Systems \#101011) at a dilution of 1:700. After washing three times with PBS for $5 \mathrm{~min}$, cells were incubated with secondary antibody, goat anti-mouse 568 (Abcam \#ab175473) at 1:1000 dilution at RT for $1 \mathrm{~h}$. Cells were then washed three times with PBS for $5 \mathrm{~min}$, and incubated with DAPI at RT for $5 \mathrm{~min}$. The coverslips were sealed onto slides with Fluoromount G (Electron Microscopy Sciences). Cells were imaged with a Leica TCS SP8 laser-scanning confocal microscope equipped with a $60 \times$ oilimmersion lens. The laser intensity was set to $10 \%$ for $561 \mathrm{~nm}$ and $5 \%$ for $405 \mathrm{~nm}$. Images were quantified using Image J software. Background fluorescence from cell-free locations was subtracted from the intensity of images of entire cells and then normalized to the intensity of fluorescent microspheres $[0.3 \%$ relative intensity, InSpeck Red (580/605), Microscope Image Intensity Calibration kit, Invitrogen \#I7224] in the same image and at the same focal plane of the cells.

\section{Electron microscopy}

Chromaffin cells on glass coverslips were fixed by immersion in $2.5 \%$ glutaraldehyde, $2.0 \%$ paraformaldehyde, and $0.1 \mathrm{M}$ sodium phosphate buffer $(\mathrm{PB}), \mathrm{pH} 7.4$ for $1 \mathrm{~h}$ at RT. Cells were rinsed $5 \times 5 \mathrm{~min}$ in $\mathrm{PB}$, postfixed in $1 \%$ osmium tetroxide, $1 \%$ potassium ferrocyanide, $\mathrm{PB}$ for $1 \mathrm{~h}$ at RT, and rinsed in PB as before. Dehydration was performed in a graded ethanol series at RT and then transitioned in dry acetone $2 \times 7 \mathrm{~min}$ at RT. Fully dehydrated cells were embedded using the supplier guidelines for Durcapan ACM (Electron Microscopy Science; https://www.emsdiasum.com/microscopy/technical/datasheet/14040. aspx). Cells were infiltrated successively in three Durcupan and acetone mixtures, increasing the proportion from 1:3 to $3: 1$. Final embedding and polymerization were performed in fresh Durcupan with added accelerator for $24 \mathrm{~h}$ at $60^{\circ} \mathrm{C}$. The coverslips were floated in concentrated hydrofluoric acid for $15 \mathrm{~min}$ and the embedded cells were sectioned on a Leica EM UC6 ultramicrotome at $100 \mathrm{~nm}$. The sections were collected on pioloform coated $2 \times 1 \mathrm{Cu}$ slot $\mathrm{Cu}$ grids (EMS), and poststained with $8 \%$ uranyl acetate in $50 \%$ ethanol and Reynold's lead citrate. The sectioned samples were viewed at $80 \mathrm{kV}$ on a Philips CM120 transmission electron microscope and images acquired with an AMT BioSprint12 digital camera (Advanced Microscopy Techniques). Images were imported into ImageJ for measurement of LDCV diameter.

\section{Experimental design and statistical analysis}

Data were organized according to chromaffin cells subjected to different conditions, including WT (the control condition), WT overexpressing syp (WT+syp), syp KO, syp KO transfected with syp (syp KO+syp), syp KO transfected with syp-dC, and syp/syg DKO. Comparisons were performed between these conditions. Data analysis, plotting, and fitting were performed with the computer program Origin. Statistical analysis was performed with GraphPad. Bar graphs present mostly cell-means (Colliver et al., 2000), with the mean first computed for individual cells and then averaged across cells within a condition; standard errors are based on cell number. Parallel statistical analysis based on number of amperometric events was also performed in some cases. The appropriateness of analysis based on cell number versus event number depends on the relative contributions to error arising from variance among events versus variance among cells, as discussed in the relevant Results sections. In linear fits to cumulative spike count plots and exponential fits to PSF duration distributions, parameter error was generated by the fit performed in Origin (Figs. 2D, 6C). Statistical significance was evaluated between conditions by ANOVA using the Tukey's post hoc test or Student-Newman-Keuls post hoc test (see figure legends). Statistical significance of immunocytochemistry measurements (Fig. 1) was based on the Mann-Whitney test. Significance of differences in cumulative distributions (Fig. 4C) was evaluated with the Kolmogorov-Smirnov test. Statistical significance is presented in Results and/or figure legends.

\section{Results}

\section{Syp loss and overexpression}

To determine syp expression levels in different conditions, chromaffin cells were stained with antibody against syp and evaluated by immunocytochemistry. Strong immunofluorescence indicated that WT chromaffin cells express syp (Fig. 1A, second row). The distribution of syp immunostaining was spatially distinct from the nuclear stain DAPI, indicating a cytoplasmic location (Fig. 1A, third and fourth rows). Syp overexpression greatly increased syp immunofluorescence (Fig. $1 A$, second column), while syp KO chromaffin cells exhibited faint syp immunofluorescence indistinguishable from background autofluorescence (Fig. 1A, third column). Syp KO cells transfected with WT syp exhibit syp immunofluorescence comparable to WT cells (Fig. $1 A$, right column). Background-subtracted total fluorescence was measured from a region of interest encompassing the entire area of individual cells and calibrated against InSpeck fluorescent beads (see Materials and Methods) to quantify syp and compare levels. Syp overexpression in WT cells significantly increased syp immunoreactivity by 2.2 -fold. Syp immunofluorescence in syp KO cells was $\sim 5$-fold below WT levels, and transfection of syp in syp KO cells resulted in levels indistinguishable from WT (Fig. 1B). Expression levels varied between cells and the distribution within each group was quite broad, especially for WT cells overexpressing syp (Fig. 1C). Although the mean levels of syp immunofluorescence in WT and syp $\mathrm{KO}+$ syp were similar, the distribution was broader in WT. These results verify that genetic ablation and overexpression have the expected outcomes on syp levels. The cytoplasmic location and punctal pattern support a vesicular localization of syp, and are consistent with prior work demonstrating the presence of syp on LDCVs (Obendorf et al., 1988; Fournier et al., 1989; Winkler, 1997; Fukuda et al., 2002; González-Jamett et al., 2010).

\section{Spike frequency}

Amperometry recordings reported the release of catecholamine from chromaffin cells depolarized by high $\mathrm{KCl}$ ejected from a nearby micropipette. Release was observed for all conditions tested, including WT, WT overexpressing syp (WT+syp), syp $\mathrm{KO}$, syp KO transfected with syp (syp KO+ syp), syp KO transfected with syp-dC (syp comprising the four TMDs and lacking the $\mathrm{C}$ terminus), and syp/syg DKO (Fig. 2A). The discrete spikelike events in these recordings register the fusion of single vesicles (Wightman et al., 1991). We calculated the frequency with which vesicles fuse by counting the number of spikes with amplitudes $\geq 4 \mathrm{pA}$ elicited by the first $\mathrm{KCl}$ stimulation, and dividing this number by the recording time during and after $\mathrm{KCl}$ application (a total of $20 \mathrm{~s}$ ). This frequency was then averaged over cells to produce a cell-mean spike frequency (Fig. $2 B$ ). In WT and syp KO cells, spikes appeared with similar frequencies of $\sim 2 \mathrm{~Hz}$. Transfection of syp in either WT or syp KO cells, and transfection of syp-dC in syp KO cells reduced this frequency $\sim 2$-fold. Syp overexpression in WT produced a similar reduction which was not significant $(p=0.08)$. Although knocking out syp alone did not reduce the spike frequency, knocking out both syp and syg significantly reduced the frequency by slightly $>2$ fold (DKO in Fig. 2B).

To evaluate the overall time course of release we plotted spike number versus time, pooling all the events from each group of cells under a given condition, and normalizing to cell number. 
A

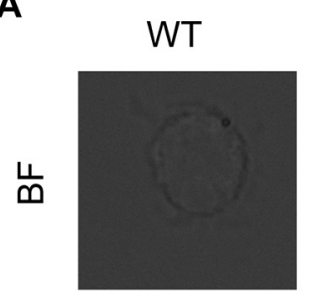

WT+Syp
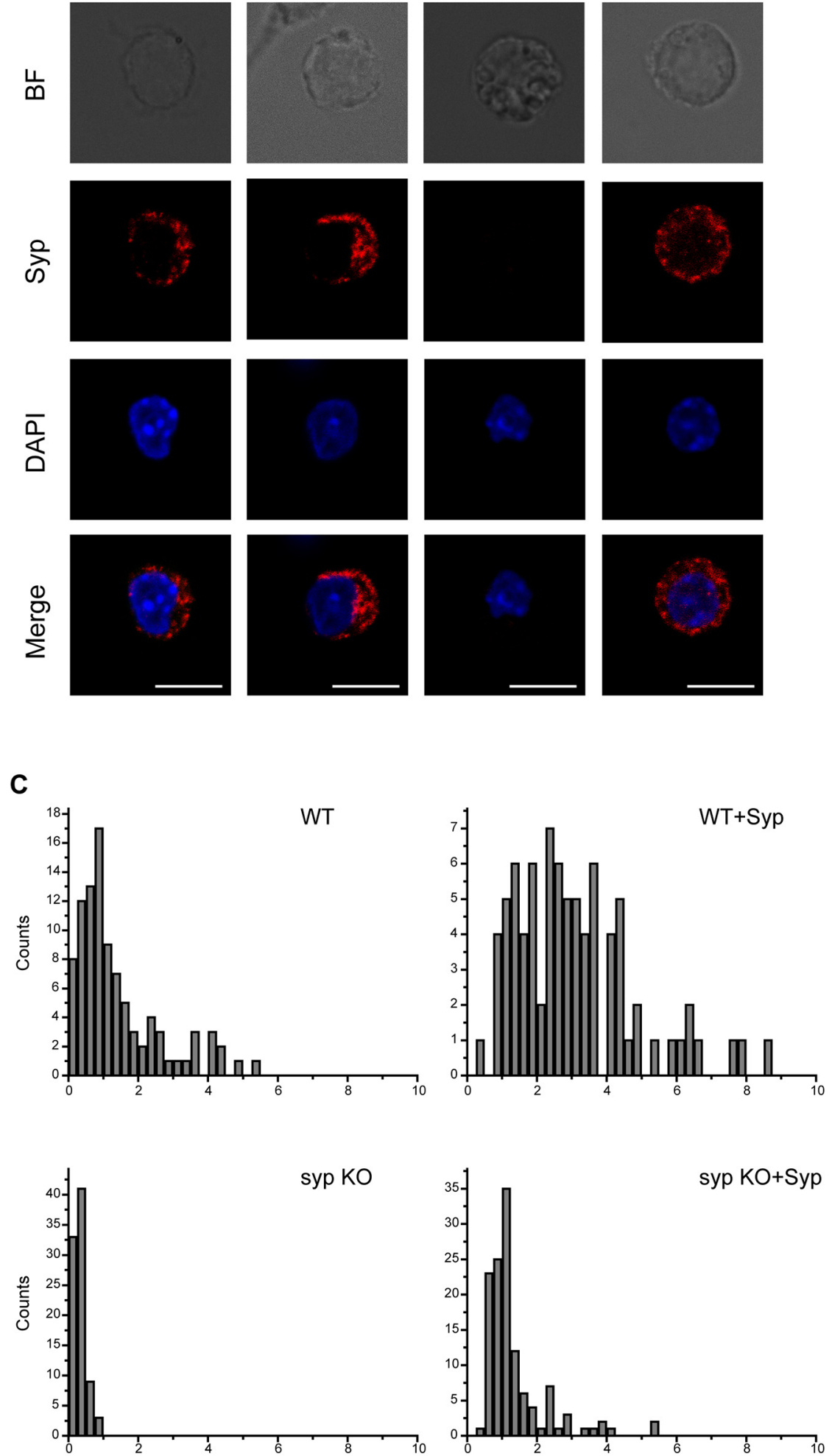

Fluorescencent intensity $(\Delta \mathrm{F} / \mathrm{F})$ syp KO
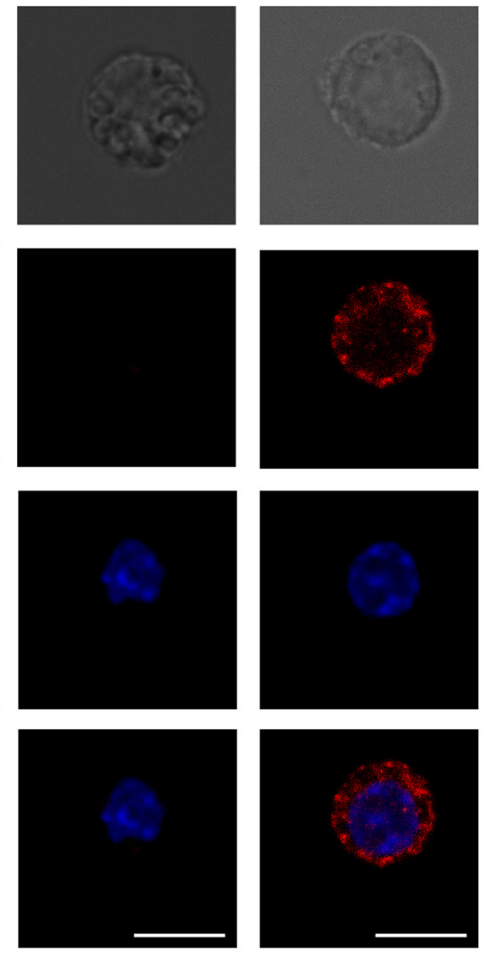

B

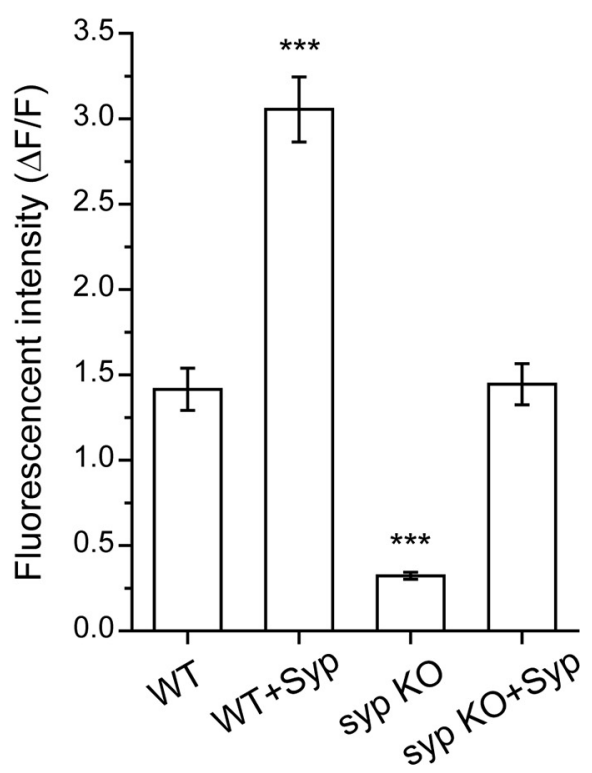

Figure 1. Syp expression. $\boldsymbol{A}$, Micrographs of WT cells, WT cells transfected with syp, syp KO cells, and syp K0 cells transfected with syp. The rows present images of bright field (BF), immunofluorescence of syp (red), DAPI (blue), and syp+DAPI (Merge). Scale bars: $7.5 \mu \mathrm{m}$. $\boldsymbol{B}$, Quantitative analysis of syp immunostaining against calibration standard corrected for background (see Materials and Methods). WT+ syp fluorescence is 2.17-fold higher than in WT, while fluorescence in syp K0+ syp is similar to that in WT. $\boldsymbol{C}$, Distribution of syp immunostaining from $\boldsymbol{B}$. Cell numbers: WT, $N=96$; WT + syp, $N=82 ;$ syp K0, $N=86$; syp KO+ syp, $N=126$; ${ }^{* * *} p<0.01$, by Mann-Whitney test. 
A $W T$

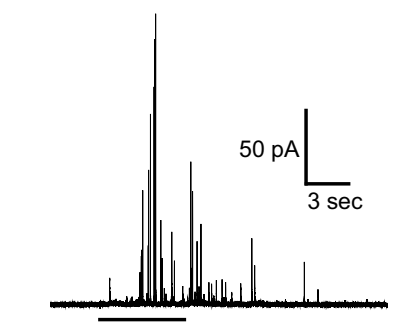

syp KO+dC

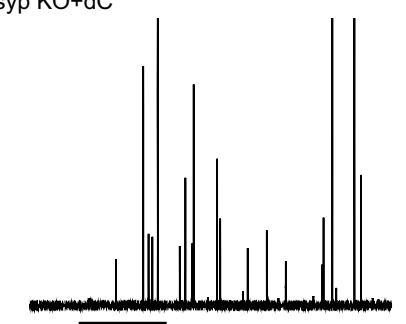

B

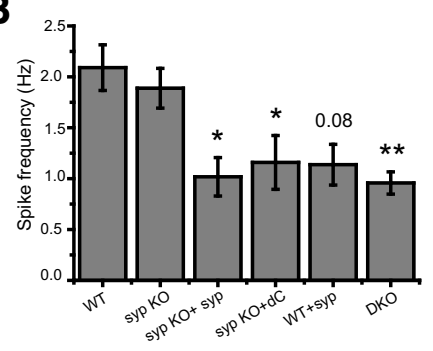

syp KO

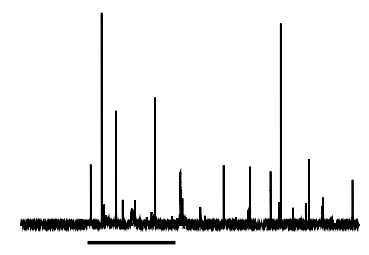

WT+syp

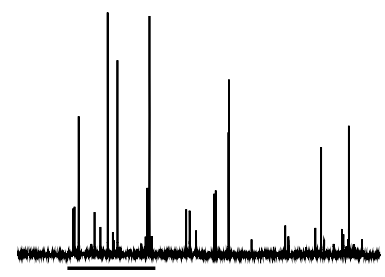

C

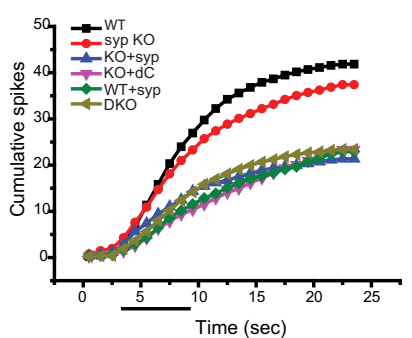

syp KO+syp

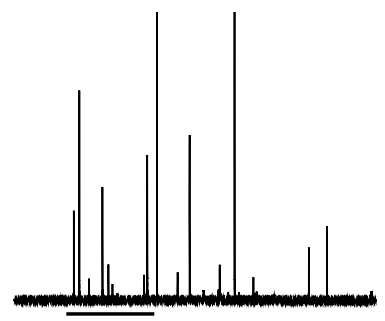

DKO

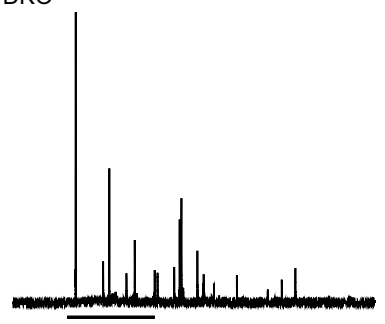

D

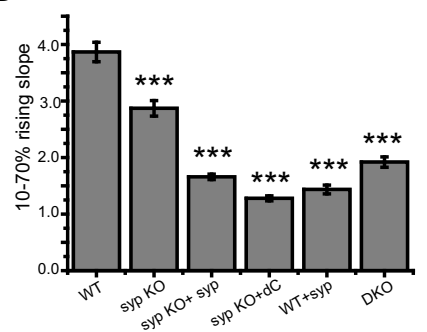

Figure 2. Amperometry recordings of catecholamine release from chromaffin cells with tetraspanner manipulations. $A$, Representative recordings from WT cells, syp K0 cells, syp K0 cells transfected with WT syp (syp KO+syp), syp KO cells transfected with syp-dC (syp KO+dC), WT cells overexpressing full-length syp (WT+syp), and syp/syg DKO cells. The lines below each trace indicate the time of depolarization by high $\mathrm{KCl}$ application. $\boldsymbol{B}$, The frequency of spikes (amplitudes $>4 \mathrm{pA}$ ) from the first stimulation, presented as cell-mean. $\boldsymbol{C}$, Pooled cumulative spike counts from the first stimulation of each cell, plotted to show fusion events versus time (normalized to cell number). As in $\boldsymbol{B}$, the line below indicates the time of depolarization. $\boldsymbol{D}$, The slope of the rise from $10 \%$ to $70 \%$ of the plateau from the cumulative plots in $C$. Cell numbers: WT, $N=77$; syp K0, $N=75 ;$ syp K0+Syp, $N=53 ;$ syp K0+dC, $N=41 ;$ WT+ syp, $N=29 ;$ DKO, $N=72$ cells; $* p<0.05, * * p<0.01, * * * p<0.001$, by one-way ANOVA with the Tukey's post hoc test.

These spike count plots increased approximately linearly during depolarization and more slowly after depolarization ceased (Fig. $2 \mathrm{C}$, horizontal black line below indicates time of $\mathrm{KCl}$ application). The steeply rising phases, when the spike counts increased from $10 \%$ to $70 \%$ of maximum, were fitted to lines and the slopes are displayed in Figure 2D. The slopes were all significantly lower than in WT. Syp KO reduced the slope by $\sim 20 \%$, and $\sim 2$-fold reductions of similar magnitude were seen with DKO, syp transfection in WT or syp KO cells, and syp-dC transfection in syp KO cells. The effects on frequency (Fig. $2 B$ ) and slope (Fig. 2D) were qualitatively similar, but the reductions in slope were statistically more robust. This difference reflects the fact that frequency was a cell-mean, and this made the statistical analysis more conservative. By contrast, the errors in the slope were much smaller because all the events for a given condition were pooled. These two measures of frequency illustrate the distinction between cellbased and event-based analysis of amperometry data (Colliver et al., 2000).

Both forms of analysis support the conclusion that ablation of syp reduced secretion slightly, and ablation of both syp and syg had a larger effect. Transfection of syp in either WT or syp KO cells reduced secretion. This effect cannot be accounted for by changes in syp levels, but may indicate a subtle effect of the different distributions of syp levels in WT versus syp KO+syp (Fig. 1). Transfection with syp and syp-dC produced similar degrees of reduction in secretion, suggesting that the TMDs alone are sufficient for this effect.

Exocytosis was lower than in WT for most conditions. Since changes in $\mathrm{Ca}^{2+}$ entry could alter secretion we patch-clamped chromaffin cells and measured voltage-gated $\mathrm{Ca}^{2+}$ current triggered by depolarizing steps. Under all of the various conditions tested for exocytosis, $\mathrm{Ca}^{2+}$ currents were similar in appearance (Fig. $3 A$ ) and the mean peak currents were indistinguishable (Fig. 3B). Furthermore, the mean currents at the end of the $100-\mathrm{ms}$ pulse were also indistinguishable (Fig. 3C). These results suggest that channel activity and inactivation are the same between groups. Although changes in more complex aspects of $\mathrm{Ca}^{2+}$ channel gating cannot be ruled out, it is unlikely that the variations in secretion result from alterations in $\mathrm{Ca}^{2+}$ channel function.

\section{Kiss-and-run versus full-fusion}

The shapes of amperometric single-vesicle fusion events varied widely. Some were rapid, with sharp spike-like shapes and large amplitudes, while others were slow, with flatter shapes and smaller amplitudes. The small flatter events are displayed more clearly with an expanded current scale that clips the large spikes (Fig. 4A). The rapid rises of spikes indicate rapid expulsion of catecholamine through an expanding fusion pore, while the small events indicate slower expulsion, suggesting that with these events the fusion pore expands relatively little and closes. In fact, the total catecholamine release during events with peak $<4 \mathrm{pA}$ (a 
A

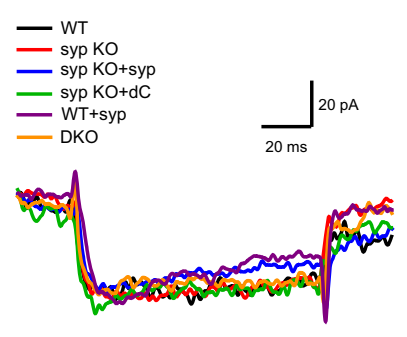

B

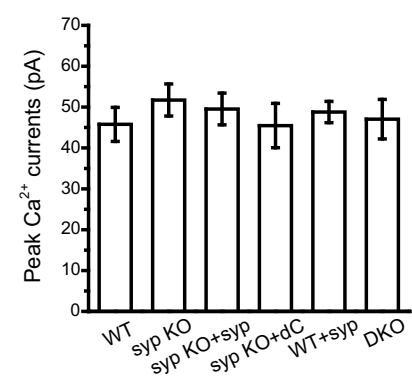

C

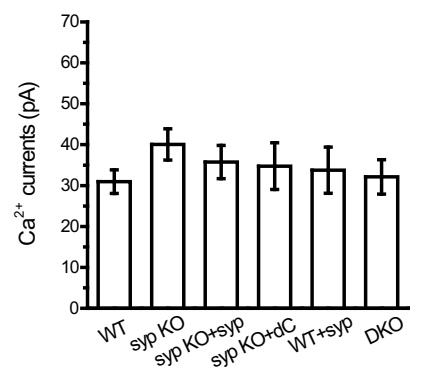

Figure 3. Calcium current. $\boldsymbol{A}$, Whole-cell recordings of $\mathrm{Ca}^{2+}$ current from individual chromaffin cells. WT (black), syp KO (red), syp K0+syp (blue), syp K0+dC (green), WT+syp (purple), and DKO (orange). Currents were evoked by pulses from -80 to $10 \mathrm{mV}$. B, Peak $\mathrm{Ca}^{2+}$ currents were averaged and the cell-means plotted. C. $\mathrm{Ca}^{2+}$ currents at the end of 100 -ms pulse were averaged and the cell-means plotted. Number of cells $=5$ (WT), 5 (syp KO), 6 (syp KO+Syp), 5 (syp K0+dC), 6 (WT+ syp), and 5 (DK0). The means were statistically indistinguishable by one-way ANOVA with Student-Newman-Keuls post hoc test.

lower cutoff for event classification discussed below) is about $1 / 4$ of the catecholamine release during events with peaks $>4 \mathrm{pA}$, indicating that either these events reflect partial content loss or they arise from a much smaller population of vesicles. These two types of events have been reported previously and attributed to different modes of exocytosis, with spikes interpreted as full-fusion and small flat events interpreted as kiss-and-run (Wang et al., 2006; Chiang et al., 2014; Chang et al., 2017). We observed both modes under all conditions tested (Fig. 4A), but their frequencies varied. We examined the incidence of these two types of events under different conditions to explore the possibility that tetraspanners influence the mode of exocytosis.

Since the two types of events have very different peak amplitudes, we first analyzed amplitude to obtain a preliminary indication of whether the release mode varies. The mean peak amplitude in DKO cells was significantly lower (Fig. 4B). Some of the other conditions also appeared to have reduced amplitudes, but the differences were not significant. The standard errors in Figure $4 B$ are large because the means are cell based. As noted above with spike frequency, the cell-based analysis is relatively conservative because it attributes statistical variation within a given condition to differences between cells (Colliver et al., 2000). However, the events recorded from one cell are very variable. Because the number of events recorded is much greater than the number of cells, to the extent that variation among events contributes to the error, cell-based statistics overestimate the true error of a measurement and thus could fail to detect meaningful differences. Errors based on event number are much lower, so with eventbased statistics many of the differences in peak amplitude become statistically significant. We therefore examined the variations in event properties in more detail using both cell-based and event-based methods of analysis.

Figure 4C1 displays cumulative amplitude distributions. These plots showed that WT had the highest proportion of large-amplitude spikes,
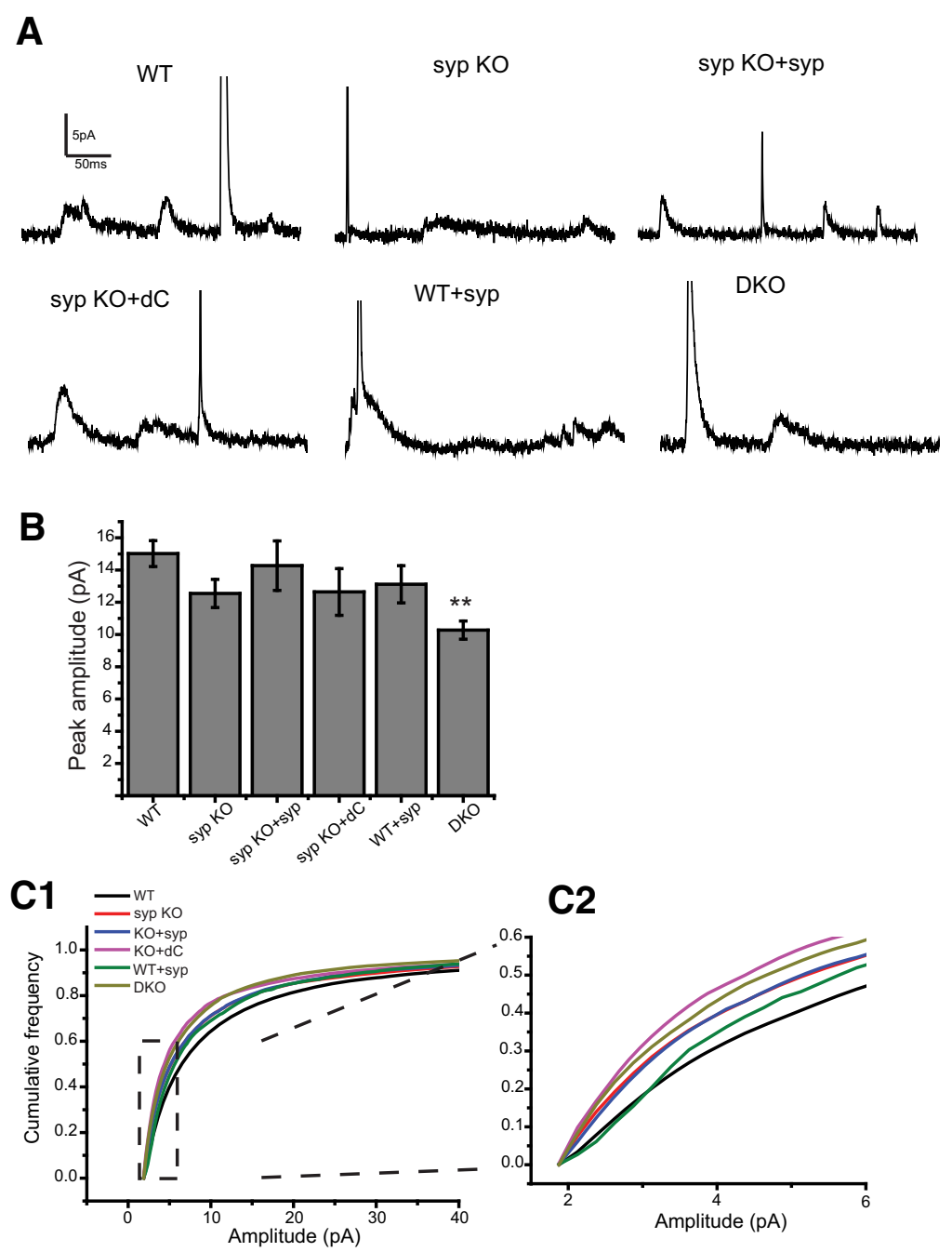

Figure 4. Two types of exocytotic events. $\boldsymbol{A}$, Amperometry recordings displayed with an expanded current scale revealed small, slow kiss-and-run events, in addition to large, rapid spikes (the peaks of the larger spikes are clipped). Both types of event were seen in all conditions. $\boldsymbol{B}$, The mean amplitudes of all events $\geq 2 \mathrm{pA}$ were calculated, with error bars based on cell number (stated in legend of Fig. 2). The peak amplitude was significantly lower in DKO. C1, Cumulative distributions of amplitudes for the indicated conditions. C2, Cumulative distributions on an expanded scale to highlight the differences. All conditions (indicated by color) exhibited significant increases in the proportion of smaller events versus WT control cells (left shifted). All distributions were significantly different as judged by the Kolmogorov-Smirnov test, except syp KO versus syp KO + syp; $* * p<0.01$, by one-way ANOVA with the Tukey's post hoc test. 
A
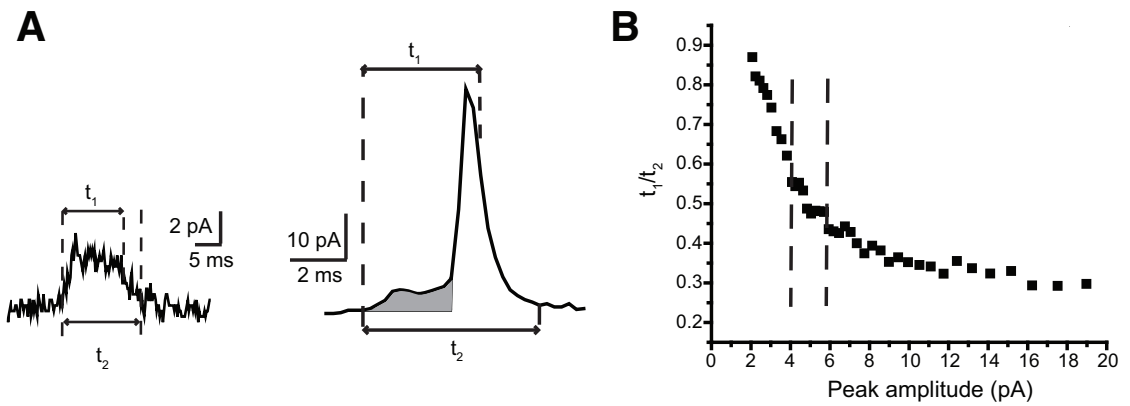

C1

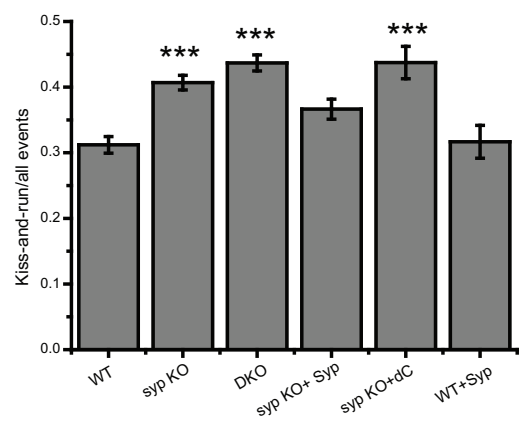

D1

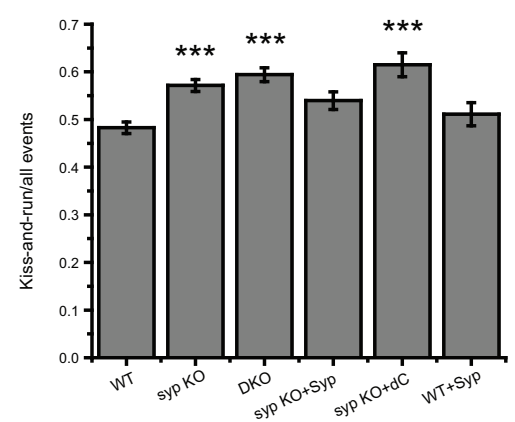

\section{C2}

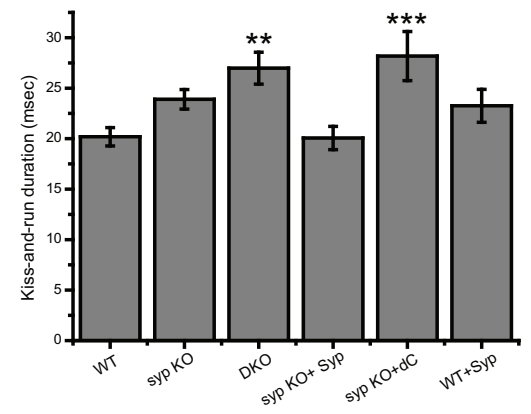

D2

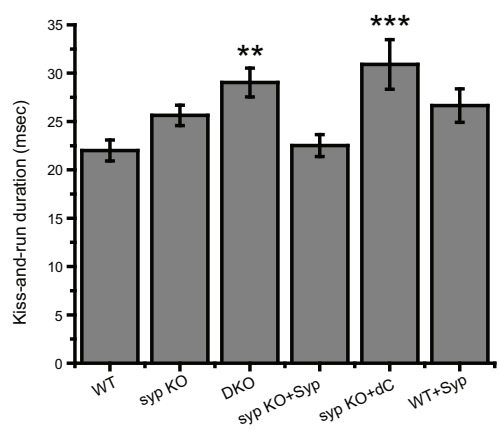

Figure 5. Classifying full-fusion and kiss-and-run events. $\boldsymbol{A}$, Representative small-amplitude kiss-and-run events (left) and large-amplitude full-fusion spikes (right). $t_{1}$ is the duration from event onset to the time where the signal passes below the average of the points within $50 \%$ of the preceding peak; $t_{2}$ indicates total duration (Wang et al., 2006). The ratio $t_{1} / t_{2}$ is close to one for kiss-and-run events and smaller for spikes. $\boldsymbol{B}$, The plot of $t_{1} / t_{2}$ versus peak amplitude from all WT cell events (200 events per bin). The dashed lines highlight a transition between two regions, with kiss-and-run events to the left and full-fusion to the right. (1, The cell-mean of fraction of kiss-and-run events (2- to 4-pA events/all events). Kiss-and-run fractions are significantly higher in syp K0, DKO, and syp KO $+\mathrm{dC}$. C2, The durations of 2- to 4-pA kiss-and-run events, computed as cell-means with cell number as in Figure 2. D1, The cell-mean of fraction of kiss-and-run events (2- to 6-pA events/all events). Kiss-and-run fractions are significantly higher in the same conditions as C1. D2, The durations of 2- to 6-pA kissand-run events; $* * p<0.01, * * * p<0.001$. One-way ANOVA with Tukey's post hoc test.

and all other conditions shifted the distributions to the left, reflecting a higher proportion of small-amplitude events. These differences can be seen more clearly by focusing on the range from 2 to $6 \mathrm{pA}$ (Fig. 4C2). The shifts relative to WT were all statistically significant as judged by the Kolmogorov-Smirnov test $(p<0.05)$. By this criterion nearly every distribution was distinct; only the syp $\mathrm{KO}$ and syp $\mathrm{KO}+$ syp distributions were indistinguishable $(p=0.09)$. This analysis of amplitude distribution revealed a trend of change toward small amplitudes. Thus, all of our manipulations of tetraspanners produced variable shifts in the mode of exocytosis toward kiss-and-run, and DKO had the greatest effect.

To analyze the shapes of events rather than amplitudes, we turned to a quantitative index to classify events (Wang et al.,
2006; Chiang et al., 2014). This is illustrated with representative events of the two types (Fig. 5A). This analysis focuses on two characteristic times: $t_{1}$ denotes the interval from onset until just after the peak, where the signal falls below the average of the points within $50 \%$ of the peak; $t_{2}$ denotes the interval from the onset to the end where the signal returns to baseline. $t_{2}$ is always greater than $t_{1}$, but with spikes the peak encompasses a relatively small part of the entire event so the disparity is greater. By contrast, $t_{1}$ and $t_{2}$ are more similar for the flatter kiss-and-run events. The ratio of the two times then serves as a useful shape parameter in distinguishing events as spikes versus kiss-and-run, allowing the classification to be made on an objective basis. $t_{1} / t_{2}$ is smaller for spikes and approaches one for kiss-and-run events. A plot of $t_{1} / t_{2}$ versus peak amplitude illustrates this trend, starting off slightly below one at low amplitude, and falling steeply as amplitude rises (Fig. 5B). This plot changes slope as amplitude increases, with most of the change occurring between 4 and $6 \mathrm{pA}$ (Fig. 5B, region marked by dashed vertical lines). This suggests that this is a transition region. Events below $4 \mathrm{pA}$ have high $t_{1} / t_{2}$ ratios and are more likely to be kiss-and-run. Above the 6-pA boundary, the events have low $t_{1} / t_{2}$ ratios and are more likely to be spikes. We therefore used these two different amplitudes as cutoffs in selecting kiss-and-run events. The low cutoff of $4 \mathrm{pA}$ minimizes contamination of kiss-and-run events by small spikes, and underestimates the fraction of kiss-and-run events, while the 6-pA cutoff has the opposite effect by minimizing the impact of kiss-and-run events on the estimation of spike number. We used these two cutoff values to calculate the fraction of kiss-and-run events for each condition and determine the cell-mean. As expected, the 4-pA cutoff produced estimates of this fraction (Fig. 5C1) that were systematically lower than the 6-pA cutoff (Fig. 5D1), with similar trends for all conditions. This quantity showed significant variations for several conditions, and both the 4-pA (Fig. 5C1) and 6-pA (Fig. 5D1) cutoffs gave the same conclusion about which conditions alter the fraction of kiss-and-run events. This approach thus provides a more robust cell-based indicator of exocytosis mode than amplitude (Fig. 4B). By this measure, syp KO and DKO cells both had higher fractions of kiss-and-run events than WT cells (Fig. $5 C 1, D 1)$. Transfection of syp in syp KO cells restored the fraction of kiss-and-run events to that seen in WT. However, transfection of syp-dC did not, and the fraction remained comparable to that seen in syp KO and DKO cells. The analysis of event fraction using both cutoffs indicates that tetraspanners influence the choice between full-fusion and kiss-and-run, and implicates the $\mathrm{C}$ terminus in this action. 
A

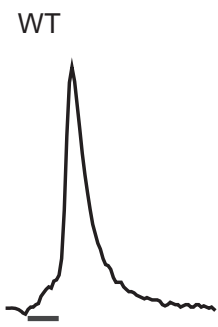

syp $\mathrm{KO}+\mathrm{dC}$ syp KO

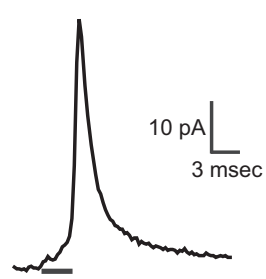

WT+syp syp KO+syp

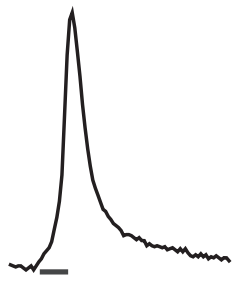

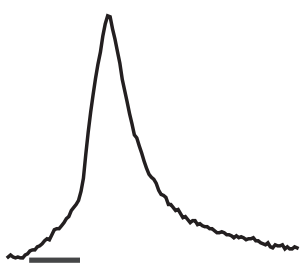
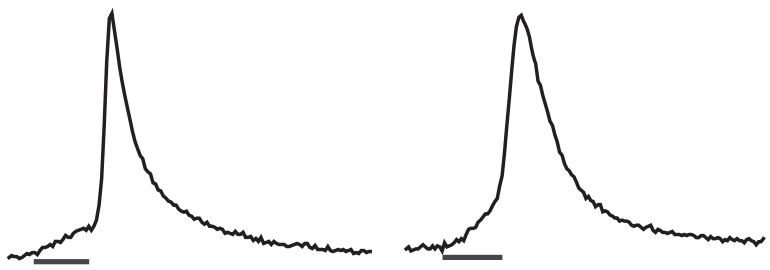

B WT

$$
\text { syp KO }
$$

syp KO+syp
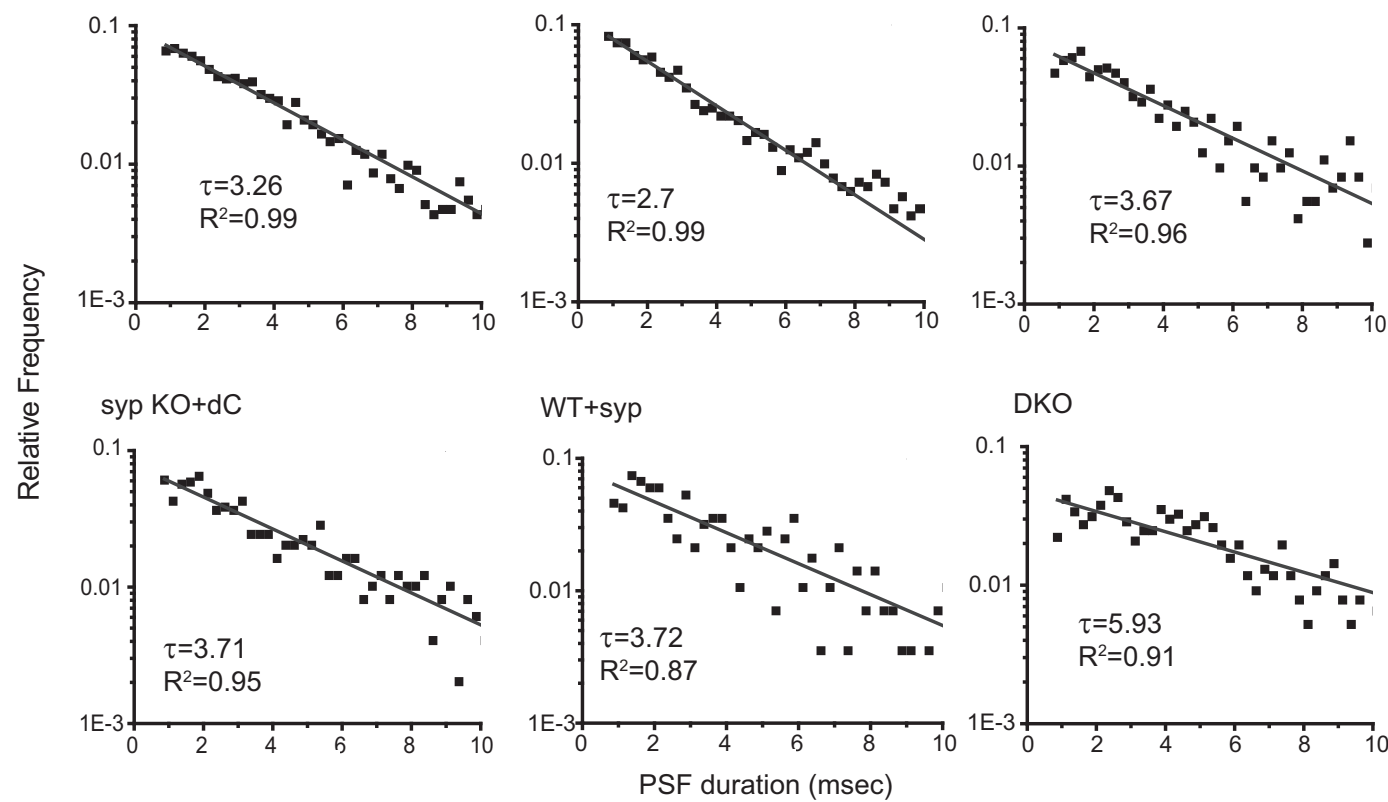

DKO

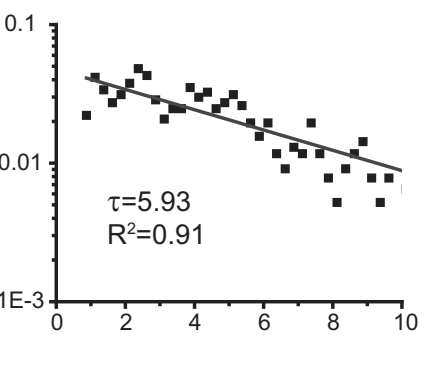

C

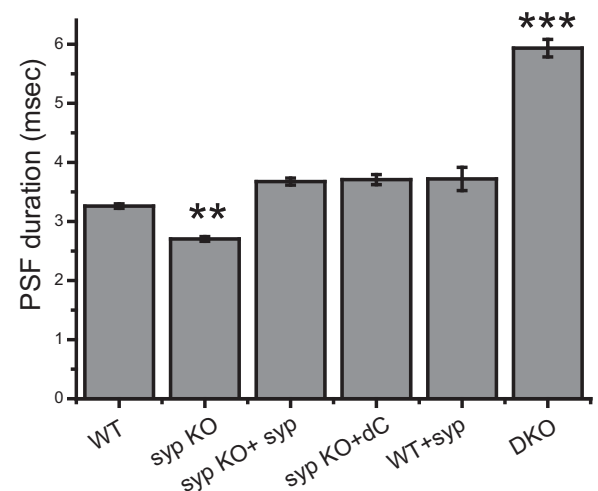

D

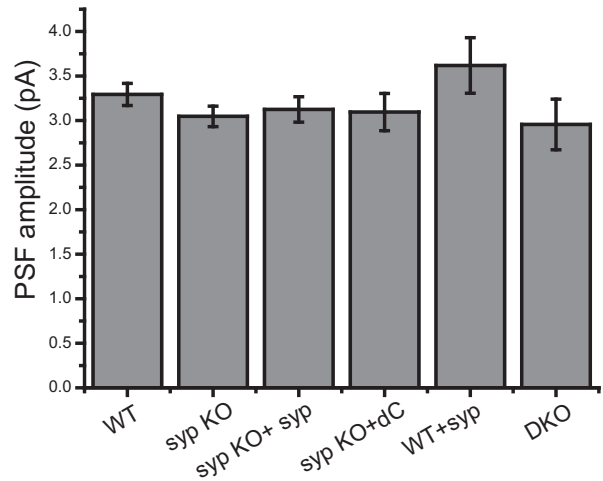

Figure 6. Initial fusion pores. $\boldsymbol{A}$, Amperometric spikes with PSF indicated by bars below each trace. $\boldsymbol{B}$, Life-time distributions of PSF are well fitted with single exponential decays (solid lines). The time constants for mean PSF duration, $\tau$, and $R^{2}$ indicated for each fit. $\boldsymbol{C}, \tau$ from the fits in $\boldsymbol{B}$ was slightly shorter in syp KO but much longer in DKO cells, and not significantly different in other conditions. D, PSF amplitudes (cell-mean) were similar in all conditions. Cell numbers and statistics as in Figure 2. 
A

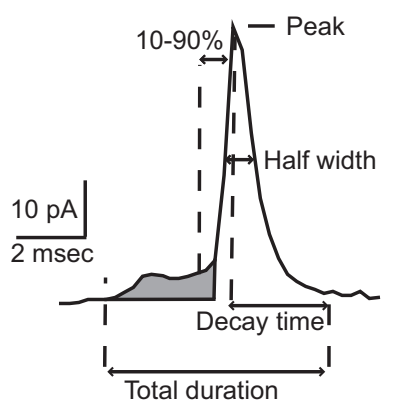

C

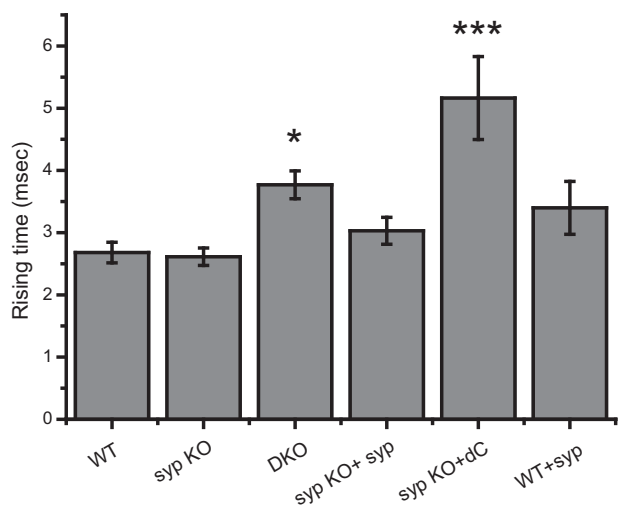

E

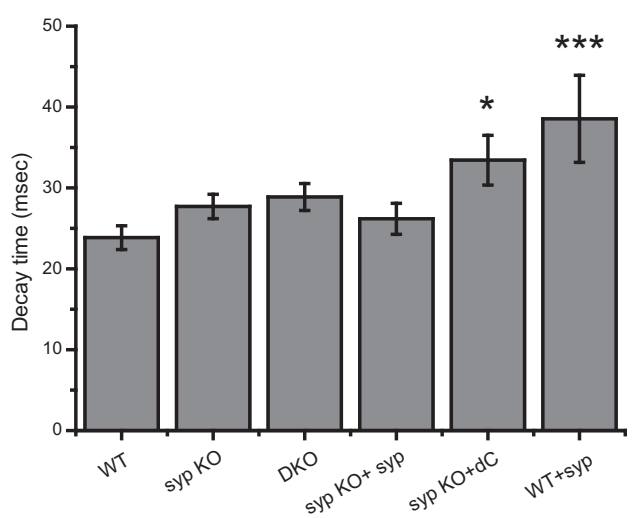

B

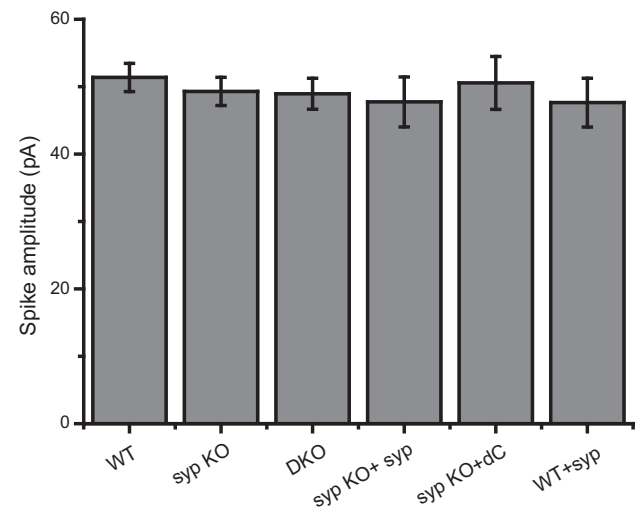

D

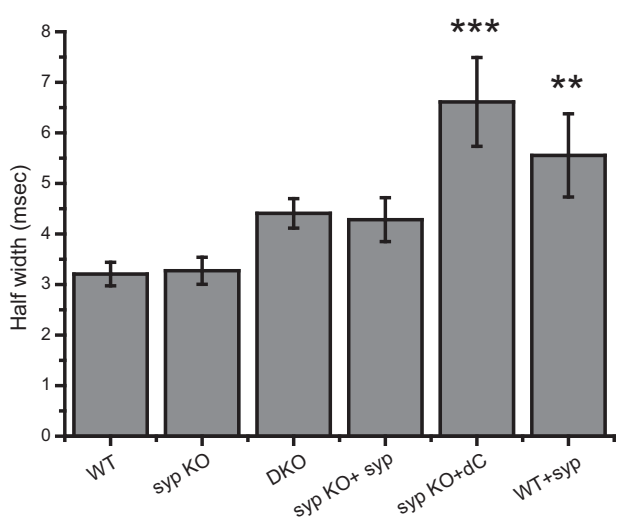

$\mathbf{F}$

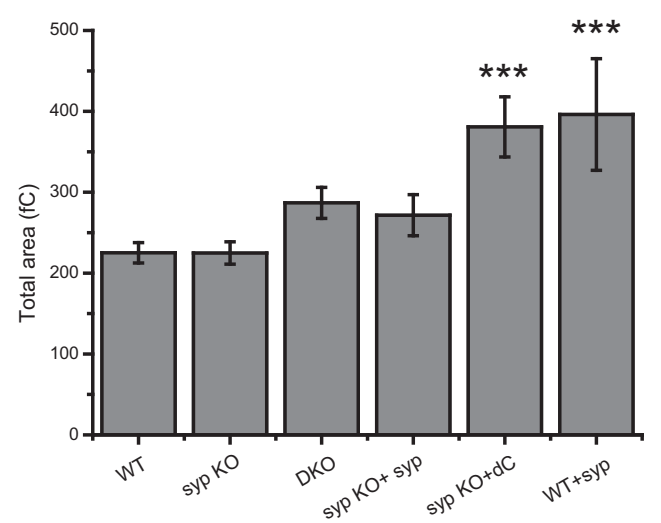

Figure 7. Spike characteristics. A, A representative spike illustrates amplitude; rising time from $10 \%$ to $90 \%$ of peak; half-width (at $50 \%$ of spike peak); and decay time from peak until return to baseline. $\boldsymbol{B}$, Mean spike amplitudes were indistinguishable in all conditions. Note that this was the mean of spikes $\geq 20 \mathrm{pA}$; by comparison, the means of all events ( $\geq 2 \mathrm{pA}$ ) varied (Fig. 4B). C, The rising time was significantly greater in DKO and syp KO+dC. D, The half-width was significantly longer in syp KO+dC and WT + syp. $\boldsymbol{E}$, The decay time was significantly longer in syp K0+dC and even more so in WT+ syp. $\boldsymbol{F}$, The total area of spikes was significantly larger in syp K0+dC and WT + Syp. Cell numbers and statistics as in Figure 2.

\section{Fusion pore stability during kiss-and-run}

We examined the stability of fusion pores during kiss-and-run by analyzing the durations of events with amplitudes $<4$ and $<6 \mathrm{pA}$. These values are presented in Figure $5 \mathrm{C} 2$ for the 4-pA cutoff and Figure 5D2 for the 6-pA cutoff, and are very similar for both. We observed a trend similar to that seen with the fraction of kiss-and-run events. Syp KO and DKO cells had longer duration kiss-and-run events than WT control cells. Transfection of syp KO cells with syp restored the durations to the WT control level, but transfection with syp-dC did not, again implicating the $\mathrm{C}$ terminus. Overexpressing syp in WT cells, which had no effect on the fraction of kiss-and-run events (Fig.
$5 C 1, D 1)$, also failed to produce a significant change in their duration (Fig. 5C2,D2). Except for the case of syp KO (where an increased duration was observed that was not significant), these manipulations of tetraspanners had parallel effects on duration and fraction of kiss-and-run events.

\section{Fusion pores stability before spikes}

To evaluate the stability of fusion pores leading to spikes, we examined the durations of PSFs that appear before a spike's rapid upstroke. The PSF represents a low level of flux through an initial fusion pore, which then expands to produce a spike (Chow et al., 1992; Jankowski et al., 1993). We observed PSF under all 
A

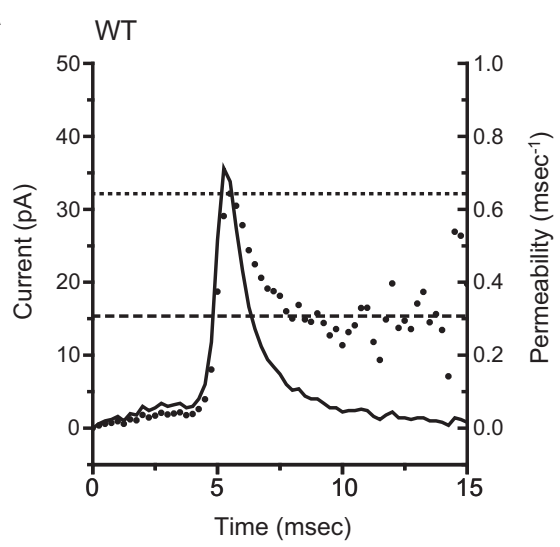

B

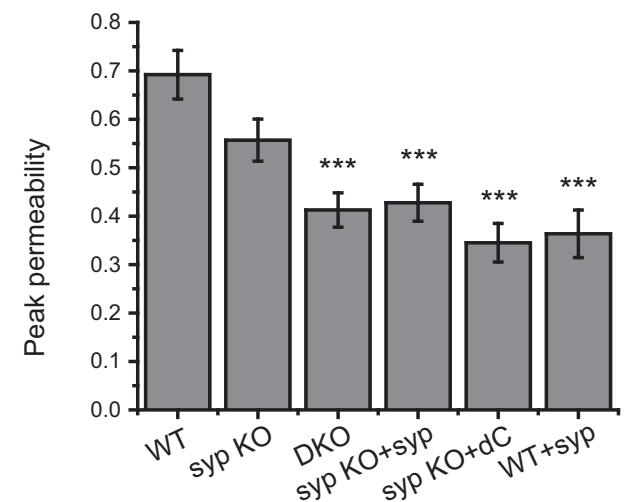

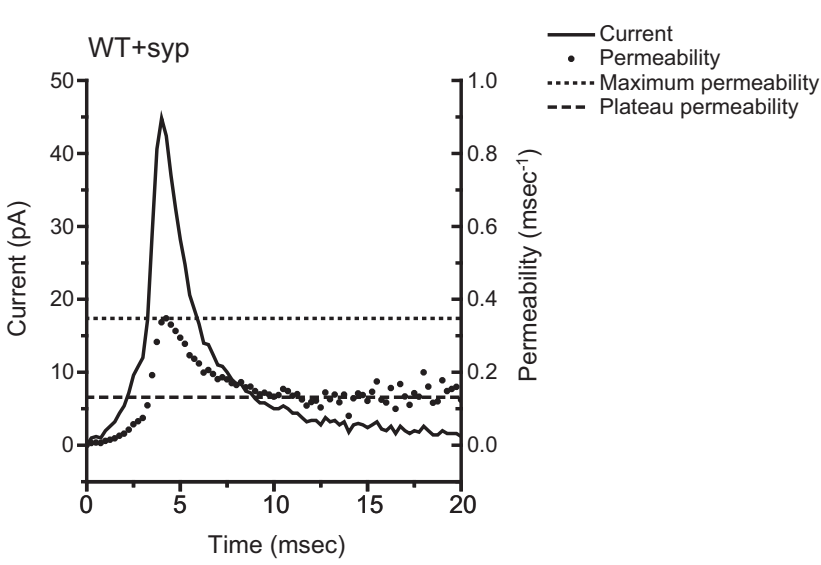

C

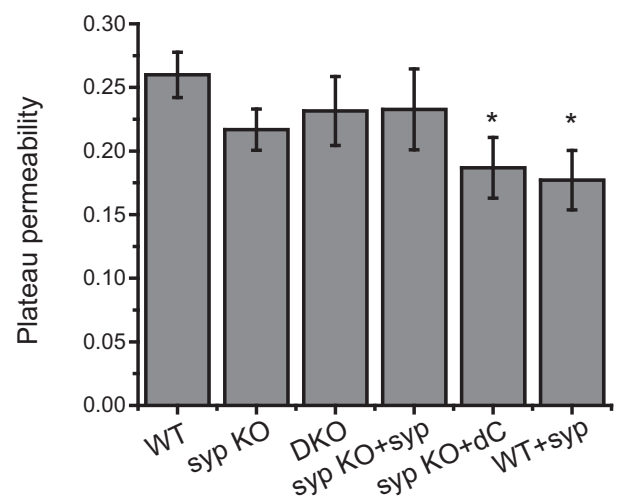

Figure 8. Late-stage fusion pores. $\boldsymbol{A}$, Transformation of spike to permeability for a WT and WT+ syp spike by the equation in text. Amperometric current (solid trace) was used to calculate permeability (dotted trace). Dotted and dashed lines show peak and plateau permeability, respectively. $\boldsymbol{B}$, Bar graph of peak permeability, which was significantly lower in DKO, Syp K0+Syp, syp K0+dC, and WT+Syp cells. C, Bar graph of plateau permeability, which was significantly lower for syp K0+dC and WT + syp. Cell numbers as in Figure $2 ; * p<0.05, * * * p<0.001$. One-way ANOVA with Tukey's post hoc test.

conditions tested (Fig. 6A, bars) and fitted their lifetime distributions to exponential decays to obtain estimates of mean duration (Jackson, 1992; Wang et al., 2001; Fig. 6B). In syp KO and DKO cells, the mean PSF duration differed significantly from WT control cells, while the other conditions had no effect. In syp KO cells the mean PSF duration was slightly shorter, and in DKO cells the mean PSF duration was almost twice as long as in WT (Fig. 6C). This suggests that tetraspanners play a role in the kinetic transitions of initial fusion pores. Since initial fusion pores can terminate by closure or expansion (Wang et al., 2001), tetraspanners could influence one or both of these rates. Ablating only syp results in briefer PSF durations (syp KO in Fig. 6), suggesting that syg, which is still present in these cells, can accelerate these rates more than syp. Transfecting syp KO cells with either syp or syp-dC restored the PSF duration to that seen in WT. Thus, the rescue of this function does not depend on the $\mathrm{C}$ terminus, and indicates that the action on initial fusion pores depends on the TMDs. The amplitudes of PSF were the same under all conditions tested (Fig. 6D), suggesting that the size of the initial fusion pore is not influenced by tetraspanners. Note that the mean amplitudes of $\sim 3 \mathrm{pA}$ are within the range for most kiss-andrun events (2-4 pA), suggesting that PSF and kiss-and-run events represent fusion pores with similar sizes.

\section{Spike shape and late-stage fusion pore dynamics}

Amperometric spikes are generally interpreted as a rapid loss of vesicle content after the fusion pore has expanded. However, their decays are too slow to be explained as catecholamine diffusion from a point on the cell surface to the amperometry electrode (Wightman et al., 1995; Schroeder et al., 1996; Jackson et al., 2020). Furthermore, spike shape can be influenced by many exocytosis proteins (Fisher et al., 2001; Barclay et al., 2004; Neco et al., 2008; González-Jamett et al., 2010, 2013; Trouillon and Ewing, 2013; Bretou et al., 2014; Shaaban et al., 2019), suggesting that fusion pores can be regulated after they have expanded. For events that were clearly classified as spikes $(\geq 20 \mathrm{pA})$ and therefore attributable to full-fusion, we observed that manipulations of tetraspanners altered their shape. We measured a number of features of these spikes (Fig. 7A) and plotted cell-means. The peak amplitudes were the same under all conditions (Fig. $7 B$ ), indicating that the $\geq 20$-pA cutoff effectively excludes kiss-and-run events (Figs. 4, 5). We also examined $10-90 \%$ rise time (Fig. $7 C$ ), half-width (Fig. $7 D$ ), decay time (Fig. $7 E$ ), and total area (Fig. $7 F$ ). The rise time in DKO cells was significantly longer than in WT, and transfection with syp-dC resulted in even longer rise times, but rise times in syp KO cells, syp KO cells transfected with syp, and WT cells overexpressing syp were indistinguishable from WT (Fig. 7C). The half-width, decay time, and total event area were all significantly greater in syp $\mathrm{KO}$ cells transfected with syp-dC, and WT cells overexpressing syp (Fig. $7 D-F)$. The analysis of spike shape thus suggests that tetraspanners regulate a later stage of exocytosis, after the choice between kissand-run and full-fusion, and that the $\mathrm{C}$ terminus plays a role.

To relate the changes in spike shape to fusion pore dynamics, we used a method that tracks fusion pore evolution during the 
A

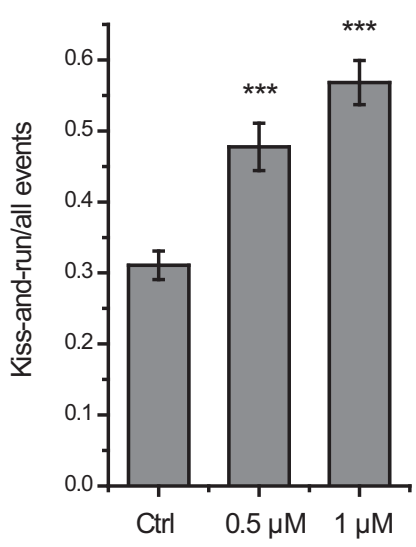

C

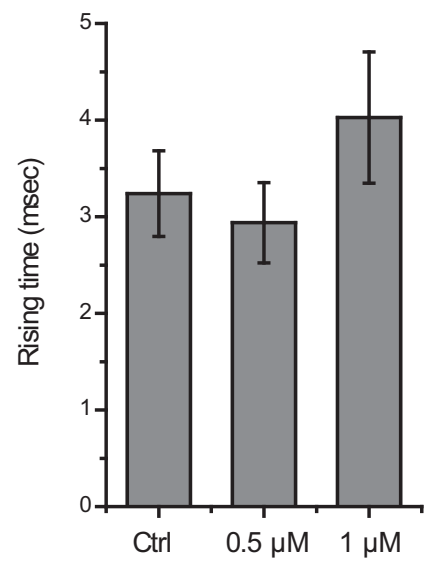

E

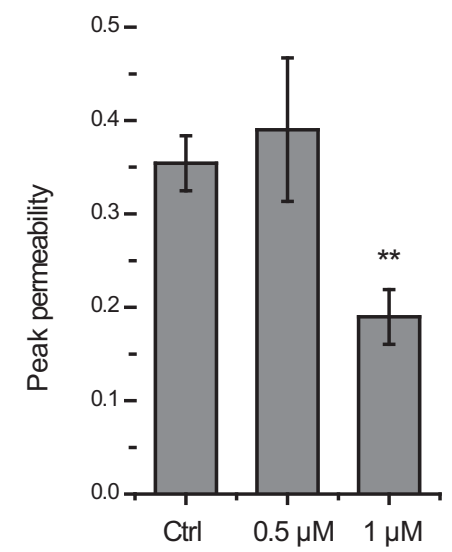

B

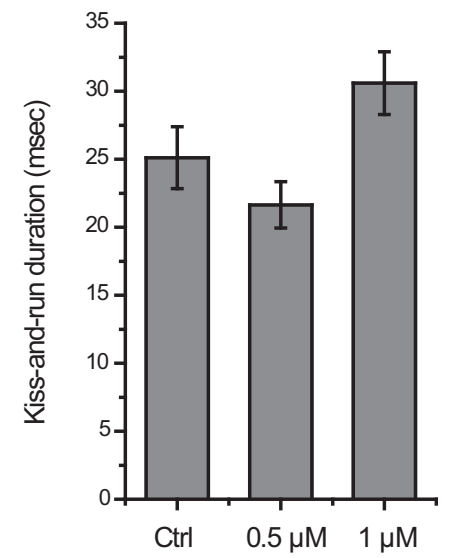

D

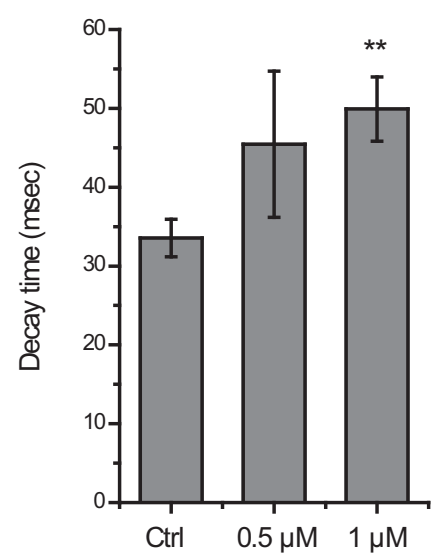

$\mathbf{F}$

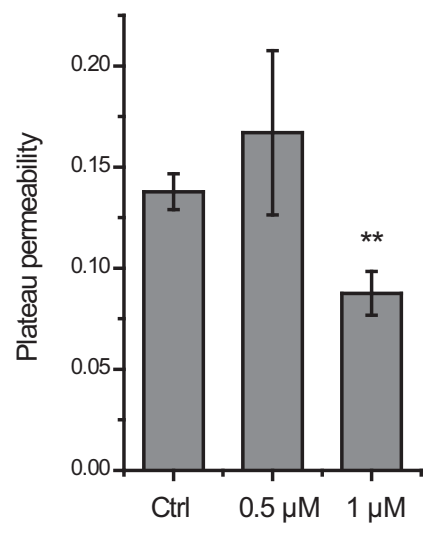

Figure 9. Inhibition of dynamin by dynasore. WT chromaffin cells were incubated in the bathing solution with $0.04 \%$ DMSO (Ctrl), or 0.5 or $1 \mu \mathrm{m}$ dynasore for $5 \mathrm{~min}$, and amperometry recordings conducted as in Figure $2 A$. $\boldsymbol{A}$, The fraction of kiss-and-run events. $\boldsymbol{B}$, Kiss-and-run duration. $\boldsymbol{C}$, Rising time. $\boldsymbol{D}$, Decay time. $\boldsymbol{E}$, Peak permeability. $\boldsymbol{F}$, Plateau permeability. Cell numbers: Ctrl, $N=29 ; 0.5 \mu \mathrm{m}, N=27 ; 1 \mu \mathrm{m}, N=31 ; * p<0.05, * * p<0.01, * * * p<0.001$. One-way ANOVA with Tukey's post hoc test.

spike (Jackson et al., 2020). With a static pore permeability $g$, the content of a vesicle with volume $V$ decays exponentially with a time constant proportional to $\mathrm{V} / \mathrm{g}$ (Almers, 1990). With a dynamic fusion pore, the time-dependent permeability $g(t)$ can be calculated from amperometric current $I(t)$ using the following transform (Jackson et al., 2020; their Eq. 7).

$$
\frac{I(t)}{Q_{0}-\int_{0}^{t} I(s) d s}=\frac{g(t)}{V} .
$$

$\mathrm{Q}_{0}$ is the total area of the event [the integral of $I(t)$ from onset to end]. This transform was applied to individual amperometric spikes, as illustrated for WT and WT overexpressing syp (Fig. 8A). The permeability plots (dotted traces) show characteristic initial low values during the PSF, followed first by a steep rise as the fusion pore expands, and then by a decline as the fusion pore constricts, ultimately settling to a plateau (Jackson et al., 2020). The peak permeabilities (Fig. 8A, dotted lines) were averaged over all spikes for a given condition and plotted in Figure $8 B$. Peak permeabilities were significantly reduced below controls for $\mathrm{DKO}$, syp KO cells transfected with syp or syp-dC, and WT cells overexpressing syp. The permeability plateaus following the spike (Fig. $8 A$, dashed lines) indicate that after the initial rapid expansion, the fusion pore constricts and settles into a metastable state in which the permeability remains roughly constant for tens of milliseconds. These plateau permeabilities were less sensitive to tetraspanner manipulations, but they were reduced in syp KO transfected with syp-dC and WT overexpressing syp (Fig. 8C). These results indicate that tetraspanners exert control over late-stage fusion pores, and that this control depends on the $\mathrm{C}$ terminus.

\section{Inhibition of dynamin by dynasore}

Because syp interacts with dynamin through its C terminus (Daly and Ziff, 2002), we tested whether inhibition of dynamin with dynasore alters catecholamine release. We prepared chromaffin cells from WT mice and performed amperometry in the absence and presence of 0.5 or $1 \mu \mathrm{M}$ dynasore, a dynamin inhibitor (Macia et al., 2006). These concentrations are well below the concentrations that dynasore inhibits chromaffin cell $\mathrm{Ca}^{2+}$ current (>50 $\mu \mathrm{m}$; Tsai et al., 2009). Both concentrations of dynasore increased the fraction of kiss-and-run events assessed with a 4-pA cutoff (Fig. 9A) but did not change their mean duration (Fig. 9B). Spike rising time was not affected (Fig. 9C), but $1 \mu \mathrm{M}$ dynasore increased the decay time significantly (Fig. 9D). The peak spike permeability and plateau permeability were both reduced by $1 \mu \mathrm{M}$ dynasore (Fig. 9E,F). (Note that the lower control values compared with Figure 8 may reflect the DMSO of control experiments $(0.04 \%$ used as vehicle for the inhibitor) or subtle differences in the genetic background of the WT animals used for these experiments). These results implicate dynamin in controlling fusion pore transitions. The increases in kiss-and-run events and spike decay times, and the reductions in peak and plateau permeability parallel the changes produced by tetraspanners 
A

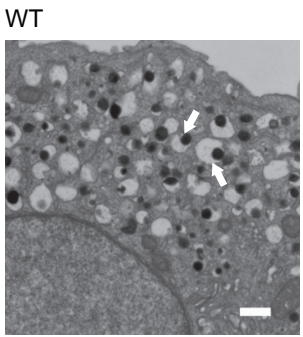

syp KO

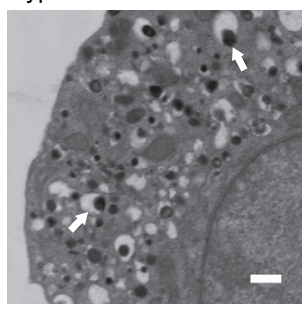

DKO

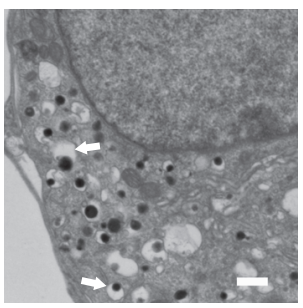

syp $\mathrm{KO}+\mathrm{dC}$

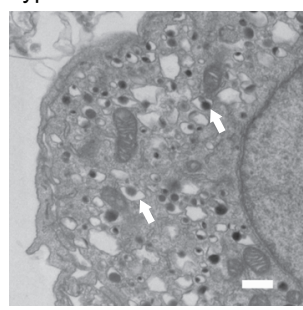

WT+syp

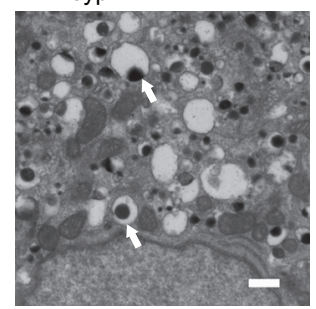

B WT

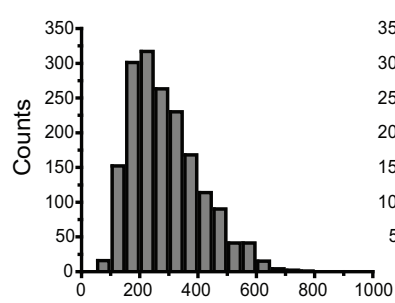

syp KO

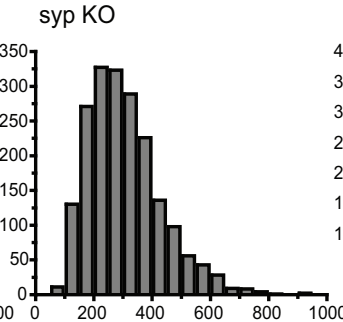

DKO

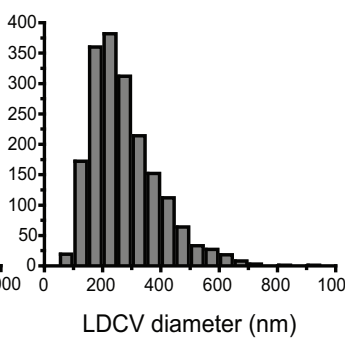

syp KO+dC

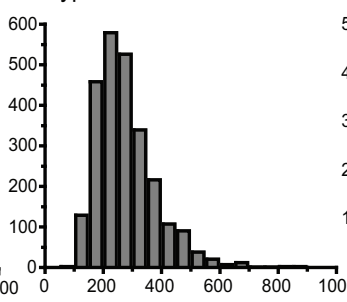

WT+syp

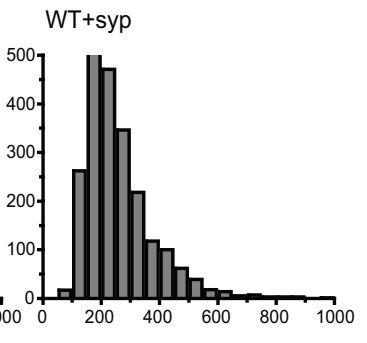

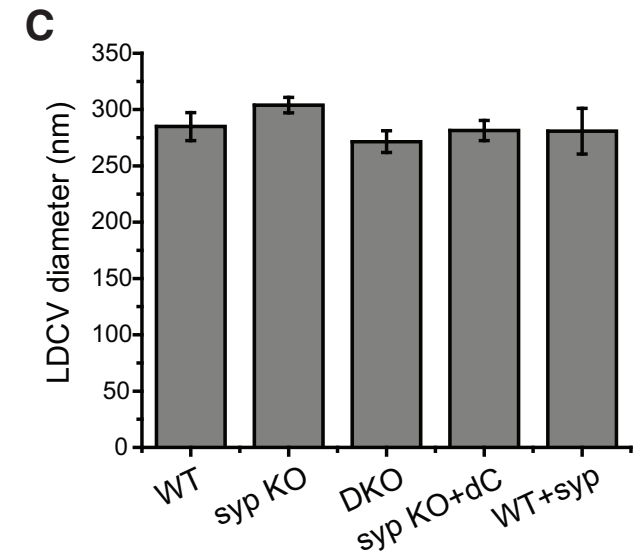

Figure 10. Vesicle sizes. $\boldsymbol{A}$, Electron micrographs of WT, syp KO, DKO, syp KO+dC, and WT + syp chromaffin cells. LDCVs are indicated by white arrows. Scale bars: $500 \mathrm{~nm}$. $\boldsymbol{B}$, Distribution of diameter in indicated groups. WT: 1755 DCVs from 18 cells; syp KO: 1963 DCVs from 18 cells; DKO: 1878 DCVs from 18 cells; syp K0+dC: 2530 DCVs from 20 cells; WT+syp: 2226 DCVs from 17 cells. C, Cell-means of diameter of indicated groups. WT: $284.93 \pm 12.45 \mathrm{~nm}$; syp K0: $303.91 \pm 6.86 \mathrm{~nm}$; DK0: $271.49 \pm 9.66 \mathrm{~nm}$; syp K0+dC: $281.35 \pm 8.93 \mathrm{~nm}$; WT+ syp: $280.77 \pm 20.31 \mathrm{~nm}$. The values were statistically indistinguishable by one-way ANOVA with Student-Newman-Keuls post hoc test.

(Figs. 5C1, 7E, 8B,C). These results are thus consistent with a role for dynamin-syp interactions in the control of fusion pores (González-Jamett et al., 2010), and suggest that the action is at an expanded, late-state pore. The large effect of the $\mathrm{C}$ terminus on spike rise times (Fig. 7C) and absence of an effect of dynasore on this property (Fig. 9C) raises the possibility of an effect of the $\mathrm{C}$ terminus that does not depend on dynamin binding.

\section{Electron microscopy and vesicle size}

Both syp KO cells transfected with syp-dC and WT cells overexpressing syp had spikes with $\sim 75 \%$ greater area than WT controls (Fig. 7F), indicating that these conditions increased the catecholamine release per event. This could reflect greater vesicle loading, and syg has been shown to interact with vesicular amine transporters to enhance their function (Egana et al., 2009). Although this form of positive functional interaction with syg cannot account for the larger area of spikes recorded from DKO cells lacking syg (Fig. 7F), more complex interactions with transporters remain a possibility. Another possible explanation for the increases in catecholamine content is an increase in LDCV size.
To test this possibility, we viewed chromaffin cells in an electron microscope and measured vesicle diameter. Images of cells from WT, syp KO, DKO, syp KO transfected with syp-dC, and WT overexpressing syp all contained characteristic LDCVs (Fig. 10A, LDCVs indicated with arrows). The diameter distributions were very similar, with peaks between 200 and $250 \mathrm{~nm}$ and tails extending to larger values. Mean diameters were all $\sim 280 \mathrm{~nm}$ and statistically indistinguishable (Fig. 10C). Thus, the differences in total amount of catecholamine released per event (Fig. $7 F)$ cannot be attributed to LDCV size. The changes in amperometric area may indicate that fusion pores close before release is complete, and that tetraspanners influence this closure process to limit content loss per event. This would then represent a very different form of kiss-and-run from that described above with small 2- to 4-pA events. Another possibility is suggested by the broad distributions of size (Fig. 10B). If small and large vesicles differ in their readiness for fusion, tetraspanners could increase the mean area of recorded spikes by increasing the relative tendency of large LDCVs to fuse compared with small LDCVs. 
A

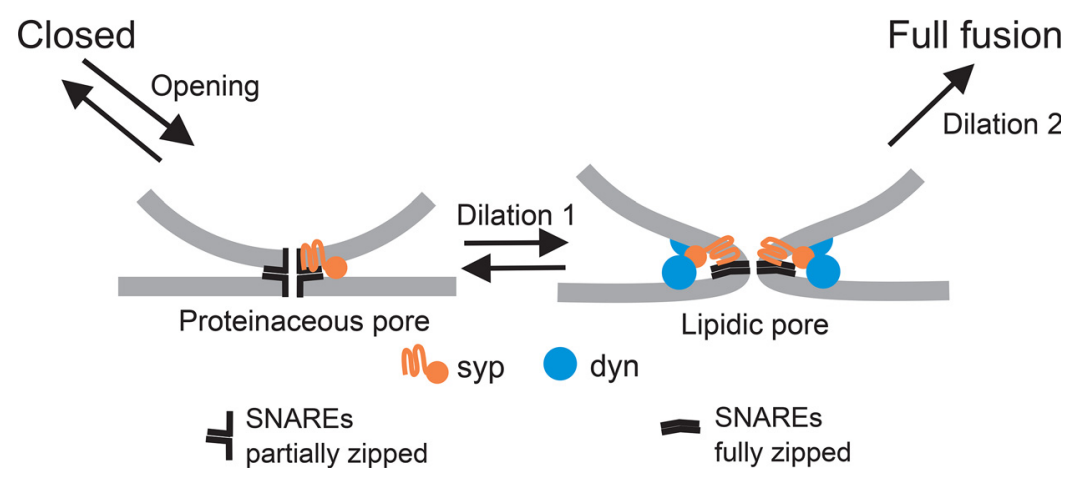

Figure 11. Syp interactions and fusion pores. A, A SNARE lined fusion pore forms with an opening transition. An interaction between syp TMDs and SNARE TMDs within a partially zipped SNARE complex of the initial fusion pore enables syp to influence early stages of fusion pores and thus PSF stability (Fig. 6). Reversal of pore opening leads to a small kiss-and-run event (Figs. 4, 5). $\boldsymbol{B}$, The first dilation step, dilation 1, expands the pore to a lipidic state, and is presumably driven by a final zipping step of the SNARE complex. An interaction between the syp Cterminal domain and dynamin can influence the stability of this lipidic pore, and determine the rate of further expansion. The further expansion of the lipidic pore is indicated as dilation 2. Reversal of dilation 1 would terminate a large, spike-like event, in a second form of kiss-and-run.

\section{Discussion}

The present study investigated the role of tetraspanners in $\mathrm{Ca}^{2+}$. triggered exocytosis. Amperometry recording of catecholamine release from mouse chromaffin cells revealed that exocytosis was altered by genetic ablation of syp and syg and transfection with syp and syp-dC. Different constructs influenced different stages of exocytosis, indicating that syp and syg have multiple roles, and control fusion pores at multiple stages of exocytosis. These proteins function in fusion pore stability and expansion, with the TMDs influencing the dynamics of small, early-stage fusion pores, and the C-terminal domains influencing large, late-stage fusion pores.

\section{Requirements for vesicle fusion}

Knocking out both syp and syg impaired but did not abolish exocytosis. This raises the question of whether the role of tetraspanners is regulatory or essential. $\mathrm{Ca}^{2+}$-triggered fusion can be reconstituted in vitro without tetraspanners (Weber et al., 1998; Jackson and Chapman, 2006). However, the possibility remains that fusion in vivo requires a tetraspanner, and that the residual secretion in DKO cells depends on other tetraspanner proteins. PC12 cells express the tetraspanners SCAMP1 and SCAMP2, and knocking them down reduced secretion (Liao et al., 2008). Disrupting the interactions of SCAMP2 with Arf6 and phospholipase D1 reduced secretion and favored kiss-and-run (Liu et al., 2005), while knocking down SCAMP1 delayed fusion pore closure (Zhang and Castle, 2011). Thus, SCAMPs could account for the residual secretion in DKO chromaffin cells.

The less frequent fusion events in DKO cells suggests a role in an early step such as docking or priming or pore opening. Transfection with syp in syp KO and WT cells also reduced the frequency of fusion events (Fig. 2), consistent with previous work in PC12 cells showing that tetraspanner overexpression inhibits release (Sugita et al., 1999). The reduction of exocytosis by both decreased and increased expression may indicate the existence of an optimal level of expression. However, expression levels (Fig. 1) did not correlate with event frequency (Fig. 2). Changes in levels of other proteins could complicate this relation, but little if any compensatory changes in the levels of other major presynaptic proteins (including synaptobrevin) were seen following ablation of syp, or syg, or both (McMahon et al., 1996; Janz et al., 1999). Interdependent expression and redundancy of function complicate the interpretations of such experiments, and point to the need to test function on backgrounds free of related forms. Tetraspanner function may also depend on context and species. Hippocampal synapses from DKO mice exhibited reduced long-term potentiation, but synaptic vesicle release was unaffected (Janz et al., 1999). In Drosophila, ablating the sole tetraspanner, a syg homolog, reduced miniature synaptic currents, increased their amplitude, and increased the paired-pulse ratio (Stevens et al., 2012).

\section{Initial fusion pores}

Tetraspanners influence both the initial fusion pore responsible for the PSF and late-stage fusion pores responsible for the spike. Initial fusion pores can terminate either by dilation or closure (Wang et al., 2001, 2006), and changing either of these rates would influence PSF duration. PSF durations became slightly shorter without syp but became quite a bit longer without both syp and syg (Fig. 6). These results suggest that tetraspanners interact with initial pores. The finding that syp with or without its $\mathrm{C}$ terminus rescued the reduction seen in syp $\mathrm{KO}$ suggests that this action depends primarily on tetraspanner TMDs. It is interesting that removing syp reduced the PSF duration while removing both syp and syg did the opposite (Fig. 6C). If syg has a stronger accelerating effect than syp on a transition out of the initial fusion pore, then removing syp will leave syg, enabling the stronger action of this protein to shorten PSF lifetimes. The loss of syg in DKO cells then takes away the protein with the stronger accelerating effect, dramatically prolonging PSF durations.

PSF amplitudes are influenced by SNARE protein TMDs, supporting a role in initial fusion pores (Chang et al., 2017). Structural work suggests that syp TMDs could also contribute to fusion pores (Adams et al., 2015), but our finding that PSF amplitudes were not altered by tetraspanner manipulations (Fig. $6 D$ ) does not support such a role. Studies of TMD mutations in syp will provide a more critical test of this idea.

\section{Mode of release}

Ablating syp or syp + syg increased the proportion of kiss-andrun events (Figs. 4, 5C). This proportion is determined by whether an initial fusion pore expands or closes, and these results point to a role for tetraspanners at this bifurcation point. Transfection of syp KO cells with syp reduced kiss-and-run to levels seen in WT cells, but transfection with syp-dC did not (Fig. 5C). This implicates the $\mathrm{C}$ terminus in release mode. In addition to the changes in small kiss-and-run events (Figs. 4, 5), the changes in spike area (Fig. $7 F$ ) suggest another effect on release mode at a later bifurcation point. Changes in spike area indicate different amounts of catecholamine release per LDCV. Since electron microscopy ruled out changes in LDCV size (Fig. $10)$, the change in spike area could reflect either a change in intravesicular catecholamine concentration, or closure of a latestage fusion pore. Closure of larger fusion pores has been suggested previously, based on amperometry (Mellander et al., 
2012) and patch-amperometry (Alés et al., 1999), and the changes in spike area reported here could indicate that tetraspanners modulate this step. Regulating release mode has important implications for endocrine function. Keeping pores small will favor the secretion of small molecules, and allowing them to expand will allow large molecules to pass (Fulop et al., 2005). Fine control over fusion pore size will determine how long vesicles retain hormones for enzymatic processing (Bohannon et al., 2017).

\section{C-terminal domain function}

Syp and syp-dC had similar effects on some aspects of exocytosis and different effects on others. These contrasts offer insight into the roles of the TMDs and the $\mathrm{C}$ terminus in different stages of exocytosis. The TMD had a greater impact on early stages (Fig. 2) and on nascent fusion pores responsible for the PSF (Fig. 6). The C-terminal domain had a greater impact on kiss-and-run (Figs. 4, 5) and late-stage fusion pores (Figs. 7, 8). These trends implicate the TMD in initial fusion pores and the $\mathrm{C}$ terminus in late-stage fusion pores. The effects on late-stage pores likely involve dynamin, which associates with the C-termini of both syp and syg in a $\mathrm{Ca}^{2+}$-dependent manner (Daly and Ziff, 2002). Disrupting this interaction in chromaffin cells increased spike half-width and quantal size (González-Jamett et al., 2010, 2013). Inhibiting dynamin slows fusion pore dilation (Trouillon and Ewing, 2013), and dynamin mutants regulated the dilation of endocrine fusion pores to a degree that depended on their GTPase activity (Anantharam et al., 2011). Moreover, inhibition of dynamin increased the half-width and decay time of amperometric spikes in chromaffin cells but did not change rise times (Graham et al., 2002). Interestingly, in WT cells overexpressing syp, we also saw an increased spike half-width and decay time, but no change in rise time (Fig. 7). The lower plateau permeability seen with syp-dC (Fig. 8C) and dynamin inhibition (Fig. 9E,F) suggests that through its interaction with the syp $\mathrm{C}$ terminus, dynamin forms a collar that promotes expansion of the late-stage fusion pore. By sequestering dynamin, syp overexpression could also reduce expansion of late-stage fusion pores.

The actions of tetraspanners on different phases of exocytosis can be interpreted with the aid of a model comprising two fusion pores states (Fig. 11). The changes in event frequency (Fig. 2) and PSF duration (Fig. 6) indicate that tetraspanners act on initial fusion pores through their TMDs (Fig. 11A). The initial fusion pore then transitions to a larger lipidic fusion pore (Fig. $11 B$, dilation 1), possibly driven by SNARE complex zipping (Jackson, 2010). By modulating this step tetraspanners could promote fusion pore dilation and control the critical choice between dilation and closure that determines whether an event terminates with full-fusion or kiss-and-run. The interaction between the syp $\mathrm{C}$ terminus and dynamin is depicted in Figure $11 B$, with a syp-dynamin collar surrounding a lipidic pore responsible for the plateau permeability (Fig. 8). Pharmacological block of dynamin releases the expanding impact of this protein (Fig. 9E,F). Further expansion (Fig. 11B, dilation 2) leads to fullfusion. Figure 11 incorporates two forms of kiss-and-run: closure by reversal of opening terminates the initial pore (Fig. 11A), reversal of dilation 1 returns the late-stage lipidic pore (Fig. 11B) back to the initial pore.

In conclusion, the present study has revealed a number of new roles for tetraspanners. These proteins promote fusion, control the opening, closing, and expansion of fusion pores, and regulate the mode of exocytosis between full-fusion and different forms of kiss-and-run. Effects on fusion pore stability suggest that these abundant membrane vesicle proteins interact with the fusion apparatus. The TMDs of syp may provide structural support for initial fusion pores, while the $\mathrm{C}$ terminus shapes latestage fusion pores. These actions provide syp and its tetraspanner homologs with multiple control points, where they can regulate LDCV exocytosis. In addition, by regulating the size of late-stage fusion pores, tetraspanners can control the selective loss of content.

\section{References}

Adams DJ, Arthur CP, Stowell MH (2015) Architecture of the synaptophysin/synaptobrevin complex: structural evidence for an entropic clustering function at the synapse. Sci Rep 5:13659.

Alés E, Tabares L, Poyato JM, Valero V, Lindau M, Alvarez de Toledo G (1999) High calcium concentrations shift the mode of exocytosis to the kiss-and-run mechanism. Nat Cell Biol 1:40-44.

Almers W (1990) Exocytosis. Annu Rev Physiol 52:607-624.

Anantharam A, Bittner MA, Aikman RL, Stuenkel EL, Schmid SL, Axelrod D, Holz RW (2011) A new role for the dynamin GTPase in the regulation of fusion pore expansion. Mol Biol Cell 22:1907-1918.

Barclay JW, Aldea M, Craig TJ, Morgan A, Burgoyne RD (2004) Regulation of the fusion pore conductance during exocytosis by cyclin-dependent kinase 5. J Biol Chem 279:41495-41503.

Becher A, Drenckhahn A, Pahner I, Margittai M, Jahn R, Ahnert-Hilger G (1999) The synaptophysin-synaptobrevin complex: a hallmark of synaptic vesicle maturation. J Neurosci 19:1922-1931.

Bohannon KP, Bittner MA, Lawrence DA, Axelrod D, Holz RW (2017) Slow fusion pore expansion creates a unique reaction chamber for co-packaged cargo. J Gen Physiol 149:921-934.

Bretou M, Jouannot O, Fanget I, Pierobon P, Larochette N, Gestraud P, Guillon M, Emiliani V, Gasman S, Desnos C, Lennon-Duménil AM, Darchen F (2014) Cdc42 controls the dilation of the exocytotic fusion pore by regulating membrane tension. Mol Biol Cell 25:3195-3209.

Calakos N, Scheller RH (1994) Vesicle-associated membrane protein and synaptophysin are associated on the synaptic vesicle. J Biol Chem 269:24534-24537.

Chang CW, Hui E, Bai J, Bruns D, Chapman ER, Jackson MB (2015) A structural role for the synaptobrevin 2 transmembrane domain in dense-core vesicle fusion pores. J Neurosci 35:5772-5780.

Chang CW, Chiang CW, Jackson MB (2017) Fusion pores and their control of neurotransmitter and hormone release. J Gen Physiol 149:301-322.

Chen YA, Scales SJ, Patel SM, Doung Y-C, Scheller RH (1999) SNARE complex formation is triggered by $\mathrm{Ca}^{2+}$ and drives membrane fusion. Cell 97:165-174.

Chiang N, Hsiao YT, Yang HJ, Lin YC, Lu JC, Wang CT (2014) Phosphomimetic mutation of cysteine string protein-alpha increases the rate of regulated exocytosis by modulating fusion pore dynamics in PC12 cells. PLoS One 9:e99180.

Chiang CW, Chang CW, Jackson MB (2018) The transmembrane domain of synaptobrevin influences neurotransmitter flux through synaptic fusion pores. J Neurosci 38:7179-7191.

Chow RH, von Rüden L (1995) Electrochemical detection of secretion from single cells. In: Single-channel recording (Sakmann B, Neher E, eds), pp 245-275. New York: Plenum.

Chow RH, von Rüden L, Neher E (1992) Delay in vesicle fusion revealed by electrochemical monitoring of single secretory events in adrenal chromaffin cells. Nature 356:60-63.

Colliver TL, Hess EJ, Pothos EN, Sulzer D, Ewing AG (2000) Quantitative and statistical analysis of the shape of amperometric spikes recorded from two populations of cells. J Neurochem 74:1086-1097.

Daly C, Ziff EB (2002) Ca2+-dependent formation of a dynamin-synaptophysin complex: potential role in synaptic vesicle endocytosis. J Biol Chem 277:9010-9015.

Daly C, Sugimori M, Moreira JE, Ziff EB, Llinas R (2000) Synaptophysin regulates clathrin-independent endocytosis of synaptic vesicles. Proc Natl Acad Sci USA 97:6120-6125.

Edelmann L, Hanson PI, Chapman ER, Jahn R (1995) Synaptobrevin binding to synaptophysin: a potential mechanism for controlling the exocytotic fusion machine. EMBO J 14:224-231. 
Egana LA, Cuevas RA, Baust TB, Parra LA, Leak RK, Hochendoner S, Pena K, Quiroz M, Hong WC, Dorostkar MM, Janz R, Sitte HH, Torres GE (2009) Physical and functional interaction between the dopamine transporter and the synaptic vesicle protein synaptogyrin-3. J Neurosci 29:4592-4604.

Eshkind LG, Leube RE (1995) Mice lacking synaptophysin reproduce and form typical synaptic vesicles. Cell Tissue Res 282:423-433.

Fasshauer D (2003) Structural insights into the SNARE mechanism. Biochim Biophys Acta 1641:87-97.

Fisher RJ, Pevsner J, Burgoyne RD (2001) Control of fusion pore dynamics during exocytosis by Munc18. Science 291:875-878.

Fournier S, Novas ML, Trifaró JM (1989) Subcellular distribution of 65,000 calmodulin-binding protein (p65) and synaptophysin (p38) in adrenal medulla. J Neurochem 53:1043-1049.

Fukuda M, Kanno E, Saegusa C, Ogata Y, Kuroda TS (2002) Slp4-a/granuphilin-a regulates dense-core vesicle exocytosis in PC12 cells. J Biol Chem 277:39673-39678.

Fulop T, Radabaugh S, Smith C (2005) Activity-dependent differential transmitter release in mouse adrenal chromaffin cells. J Neurosci 25:73247332.

Gascón S, Paez-Gomez JA, Díaz-Guerra M, Scheiffele P, Scholl FG (2008) Dual-promoter lentiviral vectors for constitutive and regulated gene expression in neurons. J Neurosci Methods 168:104-112.

González-Jamett AM, Báez-Matus X, Hevia MA, Guerra MJ, Olivares MJ, Martínez AD, Neely A, Cárdenas AM (2010) The association of dynamin with synaptophysin regulates quantal size and duration of exocytotic events in chromaffin cells. J Neurosci 30:10683-10691.

González-Jamett AM, Momboisse F, Guerra MJ, Ory S, Báez-Matus X, Barraza N, Calco V, Houy S, Couve E, Neely A, Martínez AD, Gasman S, Cárdenas AM (2013) Dynamin-2 regulates fusion pore expansion and quantal release through a mechanism that involves actin dynamics in neuroendocrine chromaffin cells. PLoS One 8:e70638.

Graham ME, O'Callaghan DW, McMahon HT, Burgoyne RD (2002) Dynamin-dependent and dynamin-independent processes contribute to the regulation of single vesicle release kinetics and quantal size. Proc Natl Acad Sci USA 99:7124-7129.

Han X, Jackson MB (2006) Structural transitions in the synaptic SNARE complex during $\mathrm{Ca}^{2+}$-triggered exocytosis. J Cell Biol 172:281-293.

Hanson PI, Roth R, Morisaki H, Jahn R, Heuser JE (1997) Structure and conformational changes in NSF and its membrane receptor complexes visualized by quick-freeze/deep-etch electron microscopy. Cell 90:523535

Hua SY, Charlton MP (1999) Activity-dependent changes in partial VAMP complexes during neurotransmitter release. Nat Neurosci 2:1078-1083.

Hübner K, Windoffer R, Hutter H, Leube RE (2002) Tetraspan vesicle membrane proteins: synthesis, subcellular localization, and functional properties. Int Rev Cytol 214:103-159.

Jackson MB (1992) Stationary single channel analysis. Methods Enzymol 207:729-746.

Jackson MB (2010) SNARE complex zipping as a driving force in the dilation of proteinaceous fusion pores. J Membr Biol 235:89-100.

Jackson MB, Chapman ER (2006) Fusion pores and fusion machines in $\mathrm{Ca}^{2+}$-triggered exocytosis. Annu Rev Biophys Biomol Struct 35:135-160.

Jackson MB, Hsiao YT, Chang CW (2020) Fusion pore expansion and contraction during catecholamine release from endocrine cells. Biophys J 119:219-231.

Jankowski JA, Schroeder TJ, Ciolkowski EL, Wightman RM (1993) Temporal characteristics of quantal secretion of catecholamines from adrenal medullary cells. J Biol Chem 268:14694-14700.

Janz R, Südhof TC, Hammer RE, Unni V, Siegelbaum SA, Bolshakov VY (1999) Essential roles in synaptic plasticity for synaptogyrin I and synaptophysin I. Neuron 24:687-700.

Kesavan J, Borisovska M, Bruns D (2007) v-SNARE actions during $\mathrm{Ca}(2+)$ triggered exocytosis. Cell 131:351-363.

Kwon SE, Chapman ER (2011) Synaptophysin regulates the kinetics of synaptic vesicle endocytosis in central neurons. Neuron 70:847-854.

Lah JJ, Burry RW (1993) Neuronotypic differentiation results in reduced levels and altered distribution of synaptophysin in PC12 cells. J Neurochem 60:503-512.

Liao H, Zhang J, Shestopal S, Szabo G, Castle A, Castle D (2008) Nonredundant function of secretory carrier membrane protein isoforms in dense core vesicle exocytosis. Am J Physiol Cell Physiol 294:C797C809.

Liu L, Liao H, Castle A, Zhang J, Casanova J, Szabo G, Castle D (2005) SCAMP2 interacts with Arf6 and phospholipase D1 and links their function to exocytotic fusion pore formation in PC12 cells. Mol Biol Cell 16:4463-4472.

Macia E, Ehrlich M, Massol R, Boucrot E, Brunner C, Kirchhausen T (2006) Dynasore, a cell-permeable inhibitor of dynamin. Dev Cell 10:839-850.

McMahon HT, Bolshakov VY, Janz R, Hammer RE, Siegelbaum SA, Sudhof TC (1996) Synaptophysin, a major synaptic vesicle protein, is not essential for neurotransmitter release. Proc Natl Acad Sci USA 93:4760-4764

Mellander LJ, Trouillon R, Svensson MI, Ewing AG (2012) Amperometric post spike feet reveal most exocytosis is via extended kiss-and-run fusion. Sci Rep 2:907.

Neco P, Fernández-Peruchena C, Navas S, Gutiérrez LM, de Toledo GA, Alés E (2008) Myosin II contributes to fusion pore expansion during exocytosis. J Biol Chem 283:10949-10957.

Obendorf D, Schwarzenbrunner U, Fischer-Colbrie R, Laslop A, Winkler H (1988) In adrenal medulla synaptophysin (protein p38) is present in chromaffin granules and in a special vesicle population. J Neurochem 51:1573-1580

Schroeder TJ, Borges R, Finnegan JM, Pihel K, Amatore C, Wightman RM (1996) Temporally resolved, independent stages of individual exocytotic secretion events. Biophys J 70:1061-1068.

Shaaban A, Dhara M, Frisch W, Harb A, Shaib AH, Becherer U, Bruns D, Mohrmann R (2019) The SNAP-25 linker supports fusion intermediates by local lipid interactions. Elife 8:e41720.

Sørensen JB, Matti U, Wei SH, Nehring RB, Voets T, Ashery U, Binz T, Neher E, Rettig J (2002) The SNARE protein SNAP-25 is linked to fast calcium triggering of exocytosis. Proc Natl Acad Sci USA 99:1627-1632.

Sørensen JB, Nagy G, Varoqueaux F, Nehring RB, Brose N, Wilson MC, Neher E (2003) Differential control of the releasable vesicle pools by SNAP-25 splice variants and SNAP-23. Cell 114:75-86.

Sørensen JB, Wiederhold K, Müller EM, Milosevic I, Nagy G, de Groot BL, Grubmüller H, Fasshauer D (2006) Sequential N- to C-terminal SNARE complex assembly drives priming and fusion of secretory vesicles. EMBO J 25:955-966.

Stevens RJ, Akbergenova Y, Jorquera RA, Littleton JT (2012) Abnormal synaptic vesicle biogenesis in Drosophila synaptogyrin mutants. J Neurosci 32:18054-18067.

Südhof TC, Rothman JE (2009) Membrane fusion: grappling with SNARE and SM proteins. Science 323:474-477.

Sugita S, Janz R, Südhof TC (1999) Synaptogyrins regulate Ca2+-dependent exocytosis in PC12 cells. J Biol Chem 274:18893-18901.

Sutton RB, Fasshauer D, Jahn R, Brunger AT (1998) Crystal structure of a SNARE complex involved in synaptic exocytosis at $2.4 \AA$ resolution. Nature 395:347-353.

Takamori S, Holt M, Stenius K, Lemke EA, Grønborg M, Riedel D, Urlaub H, Schenck S, Brügger B, Ringler P, Müller SA, Rammner B, Gräter F, Hub JS, De Groot BL, Mieskes G, Moriyama Y, Klingauf J, Grubmüller $\mathrm{H}$, Heuser J, et al. (2006) Molecular anatomy of a trafficking organelle. Cell 127:831-846.

Trouillon R, Ewing AG (2013) Amperometric measurements at cells support a role for dynamin in the dilation of the fusion pore during exocytosis. Chemphyschem 14:2295-2301.

Tsai CC, Lin CL, Wang TL, Chou AC, Chou MY, Lee CH, Peng IW, Liao JH, Chen YT, Pan CY (2009) Dynasore inhibits rapid endocytosis in bovine chromaffin cells. Am J Physiol Cell Physiol 297: C397-C406.

Walch-Solimena C, Takei K, Marek KL, Midyett K, Sudhof TC, De Camilli P, Jahn R (1993) Synaptotagmin: a membrane constituent of neuropeptide-containing large dense-core vesicles. J Neurosci 13:3895-3903.

Wang CT, Grishanin R, Earles CA, Chang PY, Martin TFJ, Chapman ER, Jackson MB (2001) Synaptotagmin modulation of fusion pore kinetics in regulated exocytosis of dense-core vesicles. Science 294:1111-1115.

Wang CT, Bai J, Chang PY, Chapman ER, Jackson MB (2006) Synaptotagmin-Ca2+ triggers two sequential steps in regulated 
exocytosis in rat PC12 cells: fusion pore opening and fusion pore dilation. J Physiol 570:295-307.

Weber T, Zemelman BV, McNew JA, Westermann B, Gmachl M, Parlati F, Söllner TH, Rothman JE (1998) SNAREpins: minimal machinery for membrane fusion. Cell 92:759-772.

Wei S, Xu T, Ashery U, Kollewe A, Matti U, Antonin W, Rettig J, Neher E (2000) Exocytotic mechanism studied by truncated and zero layer mutants of the C-terminus of SNAP-25. EMBO J 19:1279-1289.

Wightman RM, Jankowski JA, Kennedy RT, Kawagoe KT, Schroeder TJ, Leszczyszyn DJ, Near JA, Diliberto DJ Jr, Viveros OH (1991) Temporally resolved catecholamine spikes correspond to single vesicle release from individual chromaffin cells. Proc Natl Acad Sci USA 88:10754-10758.
Wightman RM, Schroeder TJ, Finnegan JM, Ciolkowski EL, Pihel K (1995) Time course of release of catecholamines from individual vesicles during exocytosis at adrenal medullary cells. Biophys J 68:383-390.

Winkler H (1997) Membrane composition of adrenergic large and small dense cored vesicles and of synaptic vesicles: consequences for their biogenesis. Neurochem Res 22:921-932.

Xu T, Rammner B, Margittai M, Artalejo AR, Neher E, Jahn R (1999) Inhibition of SNARE complex assembly differentially affects kinetic components of exocytosis. Cell 99:713-722.

Zhang J, Castle D (2011) Regulation of fusion pore closure and compound exocytosis in neuroendocrine PC12 cells by SCAMP1. Traffic 12:600614 